Check for updates

Cite this: RSC Adv., 2020, 10, 40092

Received 12th August 2020

Accepted 27th October 2020

DOI: $10.1039 / \mathrm{d}$ Ora06952c

rsc.li/rsc-advances

\section{Lichen-like anchoring of $\mathrm{MoSe}_{2}$ on functionalized multiwalled carbon nanotubes: an efficient electrode for asymmetric supercapacitors $\uparrow$}

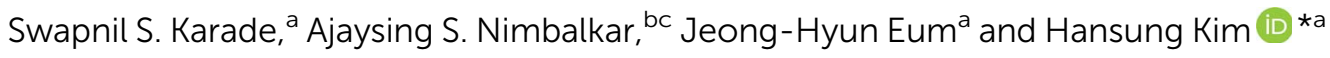

In the present study, we have developed a composite electrode of MSNT using a simple and scalable twostep scheme to synthesize a composite electrode material comprising $\mathrm{MoSe}_{2} /$ multiwalled carbon nanotubes (MoSe $\mathrm{S}_{2}$ MWCNTs) for supercapacitor applications. First, a MWCNT thin film was deposited on a stainless steel substrate by using a "dip and dry" coating technique. Subsequently, $\mathrm{MoSe}_{2}$ was deposited onto the MWCNT thin film using the successive ionic layer adsorption and reaction method. The lichen-like growth of $\mathrm{MoSe}_{2}$ on the MWCNT network provided dual charge storage and an effective ion transfer path. The composite electrode of MSNT has been studied systematically with different electrolytes and concentrations of electrolyte. As a result, the MoSe 2 /MWCNT (MSNT) electrode exhibited excellent electrochemical properties such as a specific capacity of $192 \mathrm{~mA} \mathrm{~h} \mathrm{~g}^{-1}$ and a capacitance retention of $88 \%$ after 2000 cycles in $1 \mathrm{M} \mathrm{LiCl}$ electrolyte. The results demonstrated the huge potential of the MSNT composite electrode for practical application in supercapacitors. The aqueous symmetric cell fabricated using the MSNT composite as both the anode and cathode showed

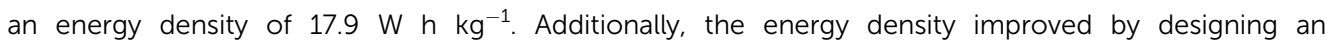
asymmetric device of $\mathrm{MSNT} / / \mathrm{MnO}_{2}$ and notably, it reveals two-fold improvement in the energy density compared to a symmetric MSNT cell. The $M S N T / / \mathrm{MnO}_{2}$-based asymmetric cell exhibited a maximum specific capacitance of $112 \mathrm{~F} \mathrm{~g}^{-1}$ with a high energy density of $35.6 \mathrm{~W} \mathrm{~h} \mathrm{~kg}^{-1}$.
\end{abstract}

\section{Introduction}

Carbon-based materials such as carbon nanotubes (CNTs), graphene, reduced graphene oxide (rGO), and activated carbon (AC) demonstrate electrochemical double-layer capacitive behavior. These materials exhibit large surface areas, less degradation, high stability, and good electrical conductivity. However, carbon-based materials suffer from low capacitance. ${ }^{\mathbf{1 , 2}}$ Nanostructured inorganic and organic materials such as metal oxides/hydroxides, metal chalcogenides, and conducting polymers show pseudocapacitive charge storage behavior. ${ }^{3-6}$ Recently, metal phosphides are coming into the picture of supercapacitive materials with a superior electrochemical performance. ${ }^{7-9}$ Zhou et al. ${ }^{7}$ developed a pseudocapacitive $\mathrm{Ni}_{2} \mathrm{P}$ nanosheet directly grown on $\mathrm{Ni}$ foam via phosphorization. The $\mathrm{Ni}_{2} \mathrm{P}$ electrode shows remarkable specific capacitance of $2141 \mathrm{~F} \mathrm{~g}^{-1}$ with a good retention of $1109 \mathrm{~F} \mathrm{~g}^{-1}$ even at a high

${ }^{a}$ Electrochemical Energy Laboratory, Department of Chemical and Biomolecular Engineering, Yonsei University, 50 Yonsei-ro, Seodaemun-gu, Seoul-03722, Republic of Korea.E-mail: elchem@yonsei.ac.kr

${ }^{b}$ Korea Research Institute of Chemical Technology, Yusong-gu, Republic of Korea ${ }^{c}$ University of Science and Technology, Daejeon, Republic of Korea

† Electronic supplementary information (ESI) available. See DOI: $10.1039 /$ dora06952c current density of $83.3 \mathrm{~A} \mathrm{~g}^{-1}$. Further, an asymmetric device of $\mathrm{Ni} 2 \mathrm{P}$ as a positive electrode and activated carbon (AC) as a negative electrode shows significant results with a specific capacitance of $96 \mathrm{~F} \mathrm{~g}^{-1}$ and energy density of $26 \mathrm{~W} \mathrm{~h} \mathrm{~kg}{ }^{-1}$. Zhang et al. ${ }^{8}$ fabricate a high-performance asymmetric supercapacitor using bimetallic phosphide of $\mathrm{Co}_{x} \mathrm{Ni}_{1-x} \mathrm{P}$ on carbon nanofibers (CNF) as a positive electrode and AC as negative electrode. It reveals significant electrochemical properties with a potential window of $1.4 \mathrm{~V}$, specific capacitance of $85 \mathrm{~F} \mathrm{~g}^{-1}$ and energy density of $32.2 \mathrm{~W} \mathrm{~h} \mathrm{~kg}^{-1}$. Also, Zhang et al. ${ }^{9}$ reported $\mathrm{CoP} / \mathrm{CNF}$ prepared by using chemical reduction and used as a negative electrode to made a high-performance asymmetric supercapacitor with a NiP/CNF as a positive electrode. Notably, the asymmetric device delivers maximum specific capacitance of $164 \mathrm{~F} \mathrm{~g}^{-1}$ with a high energy density of $56 \mathrm{~W} \mathrm{~h} \mathrm{~kg}^{-1}$ and longterm stability up to 5000 cycles. As compared to carbon-based materials, these materials show high capacitance; however, they degrade during the charge-discharge process, and hence show poor cycling stability. ${ }^{3-6,10,11}$ Therefore, various nanocomposites have been prepared in order to overcome the limitations and improve the electrochemical performance of single materials.

In the last decade, metal dichalcogenides have gained significant attention in the field of energy storage and conversion owing to their chemical, physical, optical, electrical, and 
mechanical properties. ${ }^{12-16}$ In addition, their layered graphenelike structure, higher electrical conductivity than that of metal oxides, multivalent oxidation states, earth abundance, and nontoxicity make them promising candidates for commercial applications. ${ }^{5,17,18}$ Molybdenum- and tungsten-based chalcogenides are two-dimensional (2D) materials with nanosheets and flower-like nanostructures. ${ }^{19,20}$ Soon and Loh et al. demonstrated the use of transition metal chalcogenide-based materials for supercapacitor applications. In 2007, $\mathrm{MoS}_{2}$ nanowall films with an electrochemical double-layer capacitance were reported. ${ }^{21}$ Since then, various developments have been made in the preparation of molybdenum- and tungstenbased chalcogenides for supercapacitor applications..$^{22-30}$

At present, numerous reports are available on the use of $\mathrm{MoS}_{2}, \mathrm{MoSe}_{2}$, and $\mathrm{MoTe}_{2}$ as supercapacitor electrodes. Balasingam et al. synthesized few-layered $\mathrm{MoSe}_{2}$ nanosheets for supercapacitor applications by using a hydrothermal method. When used as an electrode, these nanosheets exhibited a significant specific capacitance of $199 \mathrm{~F} \mathrm{~g}^{-1}$ at a scan rate of $2 \mathrm{mV} \mathrm{s}^{-1}$ in $0.5 \mathrm{M} \mathrm{H}_{2} \mathrm{SO}_{4}$ as the electrolyte. ${ }^{31}$ The authors extended their work by developing complex $\mathrm{MoSe}_{2} / \mathrm{rGO}$ nanosheets and obtained a higher specific capacitance of $211 \mathrm{~F} \mathrm{~g}^{-1}$ at the scan rate of $2 \mathrm{mV} \mathrm{s}^{-1} \cdot{ }^{32}$ In addition, Huang et al. reported a simple hydrothermal strategy for the synthesis of $\mathrm{MoSe}_{2}$ and its direct deposition on $\mathrm{Ni}$ foam. The resulting $\mathrm{MoSe}_{2} / \mathrm{Ni}$ foam electrode showed a high capacitance of $744 \mathrm{~F} \mathrm{~g}^{-1}$ and the faradaic charge storage behavior in $6 \mathrm{M} \mathrm{KOH}$ as the electrolyte. ${ }^{33}$ A binder-free approach based on the highly efficient electrodeposition method was successfully utilized for the deposition of 2D $\mathrm{MoSe}_{2}$ on a $\mathrm{Ni}$ foam. ${ }^{34}$ The resulting electrode showed a battery-type charge storage behavior with a capacity of $548 \mathrm{~mA} \mathrm{~h} \mathrm{~g}{ }^{-1}$. Furthermore, a highly porous net-like acetylene black-supported $\mathrm{MoSe}_{2}$ composite electrode was synthesized by using the hydrothermal method. The $\mathrm{MoSe}_{2}$-acetylene black composite electrode showed an outstanding specific capacitance of $2020 \mathrm{~F} \mathrm{~g}^{-1}$ and an excellent cyclic retention of $107 \%$ after 1500 cycles..$^{35}$ In addition to bare $\mathrm{MoSe}_{2}$ and carbon-MoSe composites, high-performance heterostructural composites such as NiSe@MoSe $e_{2}$ and $\mathrm{CoNi}_{2} \mathrm{~S}_{4}$-graphene- $\mathrm{MoSe}_{2}$ have also been reported. ${ }^{36,37}$

Developing a hybrid nanostructure with a carbon matrix is an efficient approach to improve the performance of $\mathrm{MoSe}_{2}$ electrodes. Owing to their one-dimensional (1D) structure, large surface area, good chemical stability, and mechanical flexibility, multiwalled carbon nanotubes (MWCNTs) are considered as the most promising matrix materials for supporting the host materials. $^{38-40}$ Furthermore, the 1D structure of MWCNTs provides good electrical conductivity and efficient electron transfer pathways. In addition, the MWCNT surface reduces the aggregation of the host material. Therefore, in this study, we developed a simple, scalable, and binder-free two-step chemical process. A MWCNT thin film was fabricated using the "dip and dry" coating method followed by the deposition of $\mathrm{MoSe}_{2}$ using the successive ionic layer adsorption and reaction (SILAR) method. The structure and morphology of the $\mathrm{MoSe}_{2} / \mathrm{MWCNT}$ (MSNT) composite thin film were analyzed. The charge storage behavior of the composite thin film in various electrolytes (with different concentrations) was investigated. The MSNT composite electrode showed enhanced electrochemical properties compared to the pristine $\mathrm{MoSe}_{2}$ electrode, suggesting that the MSNT composite thin film possesses great potential for application as an electrode material for supercapacitor devices. The symmetric and asymmetric cells demonstrated good electrochemical performance.

\section{Experimental}

\subsection{Materials}

Stainless steel (SS) strips (grade 306) were used as the substrate. All the commercially available analytical reagents, i.e., ammonium heptamolybdate $\left[\left(\mathrm{NH}_{4}\right)_{6} \mathrm{Mo}_{7} \mathrm{O}_{24}\right]$, citric acid $\left(\mathrm{C}_{6} \mathrm{H}_{8} \mathrm{O}_{7}\right)$, sodium borohydride $\left(\mathrm{NaBH}_{4}\right), \mathrm{Na}_{2} \mathrm{SO}_{3}$ (sodium sulfite), and selenium (Se) metal powder were purchased from SigmaAldrich and used without further treatment. Chemical vapordeposited MWCNTs were purchased from Nano Amor (Houston, USA). To prepare all the solutions, double-distilled water (DDW) was used as the solvent in all the experiments. The sodium selenosulfite $\left(\mathrm{Na}_{2} \mathrm{SeSO}_{3}\right)$ precursor was prepared using a previously optimized procedure..$^{41} \mathrm{~A}$ bath containing $5 \mathrm{~g}$ of Se mixed with $15 \mathrm{~g}$ of $\mathrm{Na}_{2} \mathrm{SO}_{3}$ in $200 \mathrm{~mL}$ of DDW was refluxed at $90{ }^{\circ} \mathrm{C}$ for $9 \mathrm{~h}$ to obtain a clear solution of $\mathrm{Na}_{2} \mathrm{SeSO}_{3}$. The prepared $\mathrm{Na}_{2} \mathrm{SeSO}_{3}$ solution was then stored in an airtight container and used as the Se source.

\subsection{Synthesis of the $\mathrm{MoSe}_{2} / \mathrm{MWCNTs}$ composite thin film}

First, functionalized MWCNTs were deposited on the SS substrate. ${ }^{6}$ In brief, the commercially available MWCNTs were purchased from Nano Amor (Houston, USA) and were then refluxed with $\mathrm{H}_{2} \mathrm{O}_{2}$ at $90{ }^{\circ} \mathrm{C}$ for $48 \mathrm{~h}$ to remove amorphous carbon derivatives and generate oxygenated functional groups. The obtained filtrate was repeatedly rinsed with DDW and dried overnight in an oven at $60{ }^{\circ} \mathrm{C}$. The functionalized MWCNTs $(0.250 \mathrm{~g})$ were mixed in a $50 \mathrm{~mL}$ solution of DDW and the Triton $\mathrm{X}$-100 surfactant (Tritonx, $100:$ DDW $=1: 100$ ). The obtained solution was sonicated for $1 \mathrm{~h}$ to obtain a stable dispersion. A mirror-polished SS substrate was vertically immersed in the solution for $10 \mathrm{~s}$ for the adsorption of the MWCNTs onto the SS substrate; the SS was then dried under an infrared (IR) lamp to evaporate the solvent. This process was repeated 12 times to obtain a terminal thickness of MWCNTs on the SS and to form adequate nucleation sites with a web-like porous nanonetwork and large surface area for the deposition of $\mathrm{MoSe}_{2}$.

In the second step, the $\mathrm{MoSe}_{2}$ thin film was deposited by alternately immersing the SS and precoated SS/MWCMT substrates in separate cationic and anionic precursors at ambient temperature. The first beaker consisted of $20 \mathrm{~mL}$ of $25 \mathrm{mM}$ ammonium heptamolybdate as the source of Mo ions with $5 \mathrm{~mL}$ of $1 \mathrm{M}$ citric acid and $1 \mathrm{~mL}$ of $1 \%$ sodium borohydride as reducing agents. The second beaker was filled with DDW to remove the loosely bound complexed cation species. The third beaker contained $25 \mathrm{~mL}$ of a $0.25 \mathrm{~N} \mathrm{Na}_{2} \mathrm{SeSO}_{3}$ solution with $1 \mathrm{~mL}$ of a $1 \%$ sodium borohydride solution as the reducing agent. The fourth beaker was filled with DDW for the second 
rinsing to remove the loosely bound molecules and unreacted ion species. The SS and precoated MWCNT substrates were sequentially immersed in the four beakers for $20,10,20$, and $10 \mathrm{~s}$, representing one complete SILAR cycle. Twenty consecutive SILAR cycles were sufficient to obtain a $\mathrm{MoSe}_{2}$ thin film with a desired thickness. The dipping area $3 \mathrm{~cm} \times 3 \mathrm{~cm}$ of the stainless-steel sample was coated by $\mathrm{MoSe}_{2}$ and MSNT thin films. The adhesion of MWCNT thin film is quite good enough to stable during SILAR process. Fig. S1† shows deposition of MSNT composite thin film which clearly shows MWCNT has good adhesion on SS substrate which does not lose a physical contact during SILAR process (ESI S1†). Basically, weight difference method was used to measure the loading of $\mathrm{MoSe}_{2}$ and MSNT thin films.

$$
m=m_{2}-m_{1}
$$

In which, ' $m$ ' is loading of active materials, ' $m_{1}$ ' is weight of substrate before deposition and ' $m_{2}$ ' is weight of substrate after deposition of thin films. Fig. 1 shows the schematic of the preparation of the MWCNTs, $\mathrm{MoSe}_{2}$, and MSNT thin films. The samples were characterized using various analytical techniques (ESI S2†).

\subsection{Electrochemical setup}

The prepared $\mathrm{MoSe}_{2}$ and MSNT electrodes were used as the working electrodes and a $\mathrm{Pt}$ wire and $\mathrm{Ag} / \mathrm{AgCl}$ as the counter and reference electrodes, respectively. The electrochemical properties of the electrodes were investigated using a potentiostat/galvanostat (PARSTAT 4000, Princeton Applied Research, USA). The mass loading played an important role in the evaluation of the specific electrochemical parameters of the electrodes. The weights of the $\mathrm{MoSe}_{2}$ and MSNT electrodes were 0.23 and $0.40 \mathrm{mg} \mathrm{cm}^{-2}$, respectively.

\section{Results and discussion}

\subsection{Reaction kinetics}

Lichen-like $\mathrm{MoSe}_{2}$ nanoparticles were deposited on the MWCNT surface via the electrostatic adsorption of cations and their reaction with anions. Initially, $\left(\mathrm{NH}_{4}\right)_{6} \mathrm{Mo}_{7} \mathrm{O}_{24}$ was used as the Mo source, which dissociated in DDW to form heptamolybdate ions. ${ }^{42}$

$$
\left(\mathrm{NH}_{4}\right)_{6} \mathrm{Mo}_{7} \mathrm{O}_{24} \rightarrow 6 \mathrm{NH}_{4}^{+}+\mathrm{Mo}_{7} \mathrm{O}_{24}{ }^{6-}
$$

After the addition of citric acid, these heptamolybdate ions formed a complex with citrate ions $\left[\mathrm{C}_{3} \mathrm{H}_{5} \mathrm{O}(\mathrm{COO})_{3}{ }^{3-}\right]$, as shown below : ${ }^{43}$

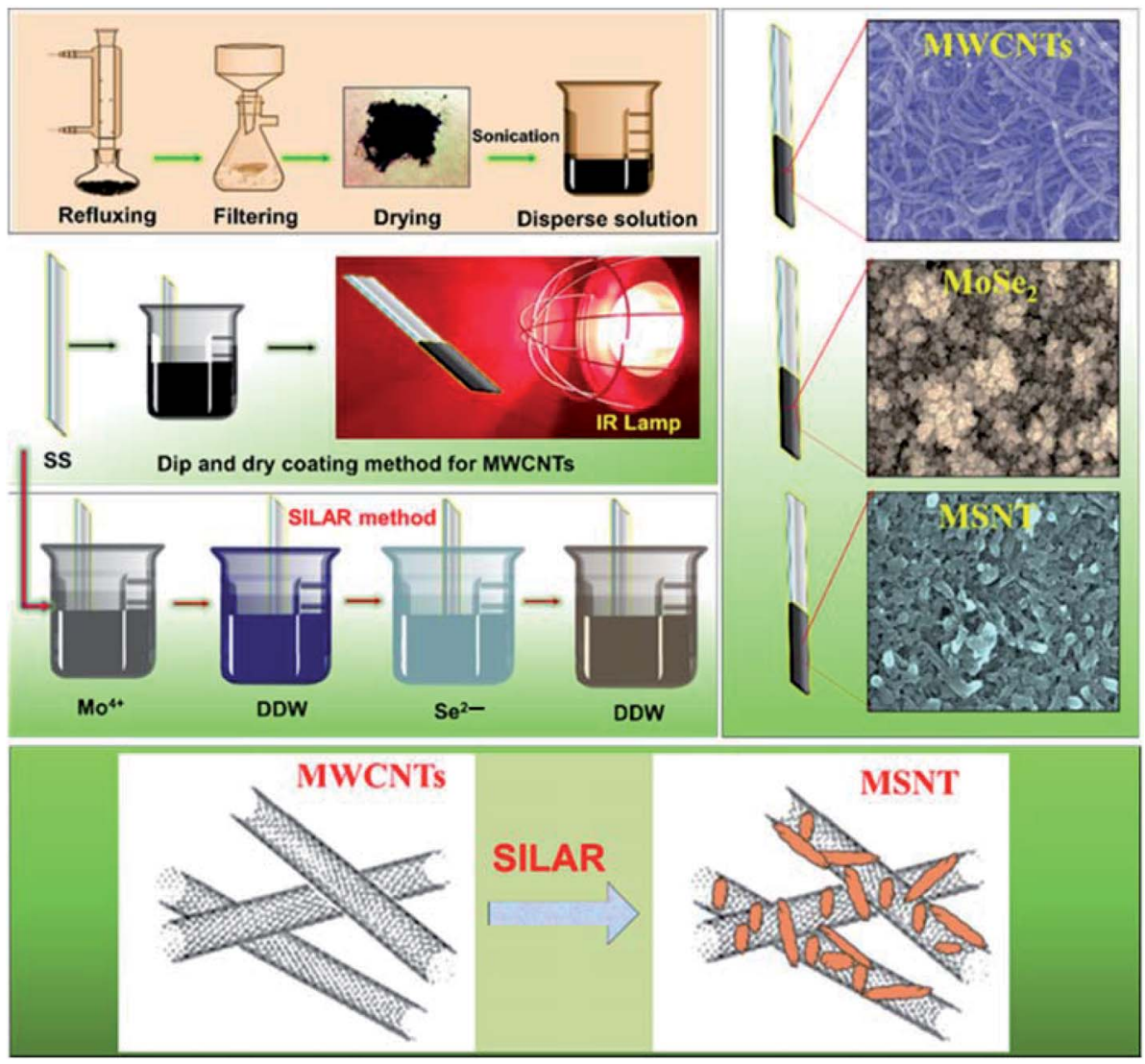

Fig. 1 Schematic of the simple and scalable synthesis of the MWCNT, MoSe ${ }_{2}$, and MSNT thin films. 


$$
\begin{aligned}
& \mathrm{Mo}_{7} \mathrm{O}_{24}{ }^{6-}+2 \mathrm{C}_{3} \mathrm{H}_{5} \mathrm{O}(\mathrm{COO})_{3}{ }^{3-} \rightarrow \rightarrow \\
& {\left[\mathrm{Mo}-2 \mathrm{C}_{3} \mathrm{H}_{5} \mathrm{O}(\mathrm{COO})_{3}\right]+12 \mathrm{O}_{2} }
\end{aligned}
$$

$\mathrm{NaBH}_{4}$ (reducing agent) reduced the $\mathrm{Mo}^{6+}$ ions in the precursor to $\mathrm{Mo}^{4+}$ according to the following reaction: ${ }^{39,41,43}$

$$
\begin{aligned}
& {\left[\mathrm{Mo}-2 \mathrm{C}_{3} \mathrm{H}_{5} \mathrm{O}(\mathrm{COO})_{3}\right] }+2 \mathrm{BH}_{4}^{-}+2 \mathrm{H}_{2} \mathrm{O} \rightarrow \\
& \mathrm{Mo}^{4+}+2 \mathrm{C}_{6} \mathrm{H}_{8} \mathrm{O}_{7}+2 \mathrm{BH}_{3}+\mathrm{O}_{2} \uparrow
\end{aligned}
$$

The bare SS and MWCNT-coated SS substrates were immersed in the aforementioned solution for the adsorption of $\mathrm{Mo}^{4+}$ ions.

The dissociation of $\mathrm{Na}_{2} \mathrm{SeSO}_{3}$ produced $\mathrm{Na}^{+}$and $\mathrm{SeSO}_{3}{ }^{2-}$, which were further reduced in the presence of $\mathrm{NaBH}_{4}$ (reducing agent) to form $\mathrm{Se}^{2-}$ ions.

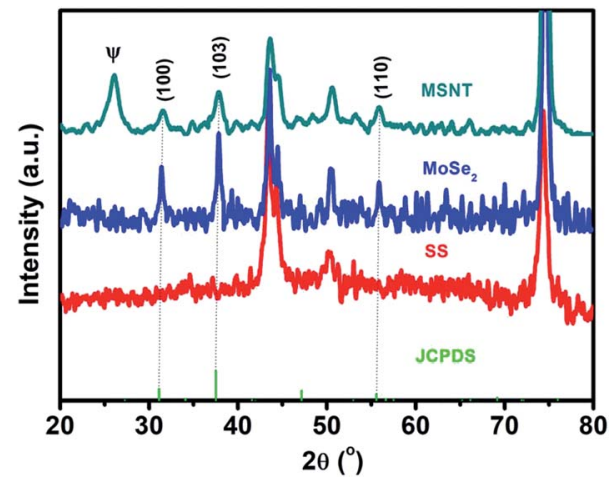

Fig. 2 XRD patterns of the $\mathrm{MoSe}_{2}$ and MSNT thin films.

$$
\mathrm{SeSO}_{3}{ }^{2-}+2 \mathrm{BH}_{4}^{-} \rightarrow \mathrm{Se}^{2-}+2 \mathrm{BH}_{3}+\mathrm{H}_{2} \uparrow+\mathrm{SO}_{3}{ }^{2-}
$$

Finally, the $\mathrm{Mo}^{4+}$ ion-adsorbed bare SS and MWCNT-coated SS substrates were immersed in the aforementioned solution containing $\mathrm{Se}^{2-}$ ions to form $\mathrm{MoSe}_{2}$.

$$
\mathrm{Mo}^{4+}+2 \mathrm{Se}^{2-} \rightarrow \mathrm{MoSe}_{2}
$$

The aforementioned process was repeated several times by immersing the bare SS and MWCNT-coated SS substrates in the respective solutions $\left(\mathrm{Mo}^{4+}\right.$ and $\left.\mathrm{Se}^{2-}\right)$ to deposit a uniform and well-adhering thin layer of $\mathrm{MoSe}_{2}$ on the substrates.

\subsection{Structural analysis}

The structures of the MSNT composite and $\mathrm{MoSe}_{2}$ thin films were analyzed using wide-angle X-ray diffraction (XRD) (Fig. 2). The films showed major diffraction peaks at $2 \theta=31.4^{\circ}, 37.8^{\circ}$, and $55.8^{\circ}$ corresponding to the (100), (103), and (110) planes of hexagonal $\mathrm{MoSe}_{2}$ (JCPDS No. 87-2419), respectively, while the other peaks listed in the JCPDS card could not be observed because of their low intensity and the relatively high-intensity peaks of the SS substrate. Furthermore, the broad peak observed at $2 \theta=26^{\circ}$ in the XRD pattern of the MSNT thin film denoted by $\Psi$ was attributable to the characteristic peak of the graphitic carbon of the MWCNTs. The surface elemental compositions of the thin films were analyzed using X-ray photoelectron spectroscopy (XPS). Fig. 3a shows the XPS survey profile of the MSNT composite film. As can be observed from the figure, the film showed peaks corresponding to the Se 3d, Mo 3d, and C 1s orbitals. This further confirmed the
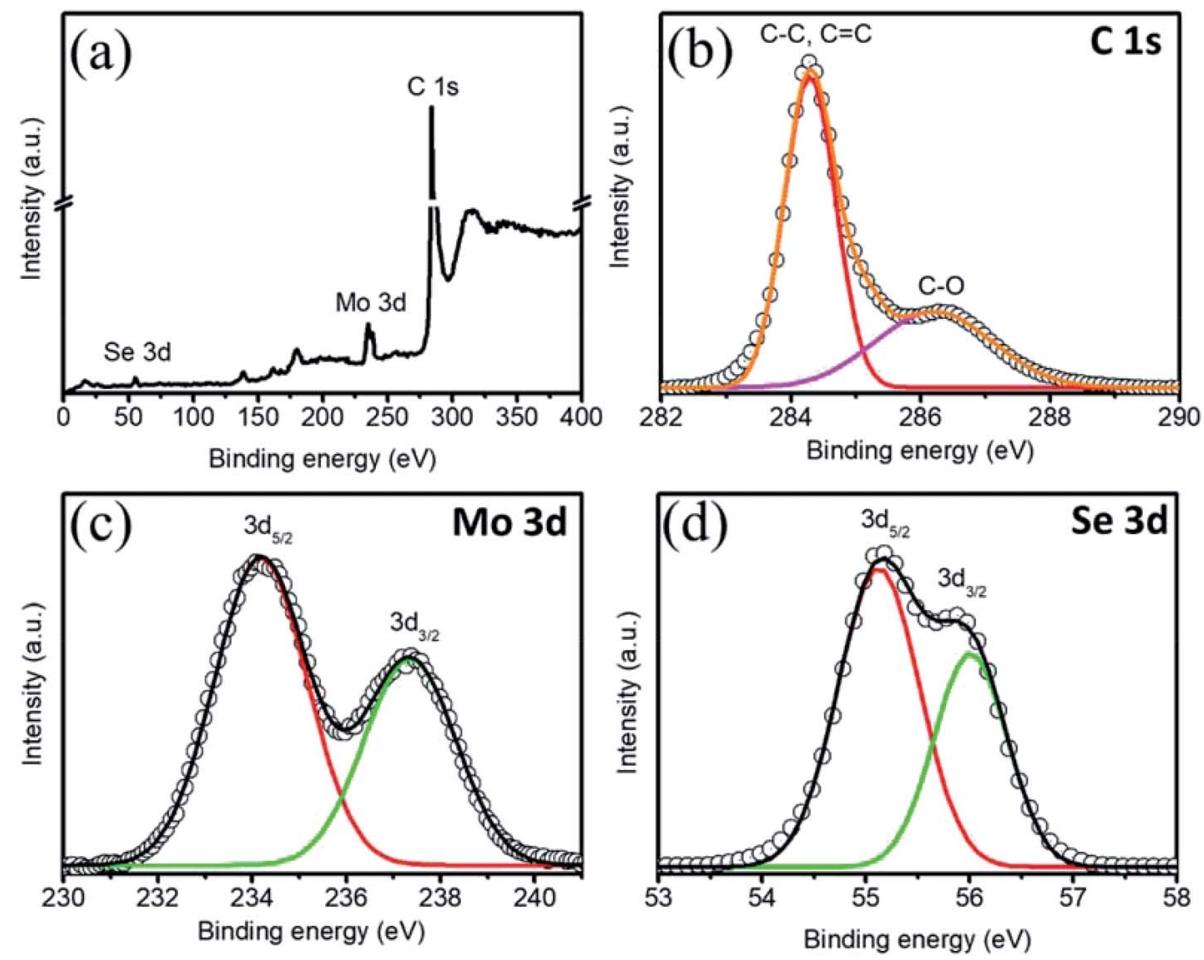

Fig. 3 (a) XPS profile of the MSNT composite. Core-level (b) C 1s, (c) Mo 3d, and (d) Se 3d XPS profiles. 
formation of the MSNT composite thin film. Fig. 3b shows the core $\mathrm{C}$ 1s profile of the film. Two prominent peaks were observed at the binding energies of 284.1 and $286.3 \mathrm{eV}$ corresponding to the graphitic carbon of the MWCNTs and the carbon-oxygen bonds, respectively. The narrow-scan Mo 3d XPS profile of the film (Fig. 3c) showed two distinct peaks at 234.2 and $237.3 \mathrm{eV}$, indicating that the oxidation state of Mo was $4+.{ }^{32,39,44-46}$ In addition, Fig. $3 \mathrm{~d}$ shows the Se $3 \mathrm{~d}$ XPS profile of the film. The Se $3 \mathrm{~d}$ peak of the composite film could be deconvoluted into two peaks at 55.2 and $56 \mathrm{eV}$, indicating that the oxidation state of Se was $2-.^{32,36}$

\subsection{Surface morphology}

The surface microstructure of a material significantly affects its charge storage capacity. Fig. 4a shows the microscopic image of the surface of the MWCNT thin film deposited on the SS substrate. Owing to its uniform network-like structure, the MWCNT thin film showed a large surface area and 1D conduction path for electron transfer. The successive cation adsorption and anion reaction resulted in the colonial growth of $\mathrm{MoSe}_{2}$ nanoparticles on the MWCNT thin film, as shown in Fig. $4 \mathrm{~b}$ and c. Electrodes with a porous structure show large surface area and numerous active sites for interaction with electrolyte ions, and hence offer significant storage ability. ${ }^{47}$ In the MSNT composite thin film, the lichen-like growth of $\mathrm{MoSe}_{2}$ on the MWCNTs (Fig. 4d and e) reduced the ion diffusion path length and exhibited strong interfacial conjugation. In addition, the porous structure of the MSNT composite provided large effective surface area for the interaction of the electrolyte ions during the electrochemical process, which in turn improved the electrochemical performance of the composite. Fig. 3f shows the energy-dispersive spectroscopy (EDS) mapping of the MSNT composite thin film, which revealed that the film consisted of $72.6 \% \mathrm{C}, 8.8 \% \mathrm{Mo}$, and $18.6 \% \mathrm{Se}$, confirmed the formation of the $\mathrm{MoSe}_{2} / \mathrm{MWCNT}$ composite structure.
The transmission electron microscopy (TEM) image of the MSNT composite is shown in Fig. 5a. It clearly reveals the lichen-like growth of $\mathrm{MoSe}_{2}$ nanoparticles on the MWCNTs. The oxygenated functional groups generated during the reflux of the MWCNTs with $\mathrm{H}_{2} \mathrm{O}_{2}$ acted as active sites for the growth of $\mathrm{MoSe}_{2}$ on the MWCNTs. Fig. 5b shows the high-magnification TEM image of the MSNT composite film. The lattice fringes with the interplanar spacings of $0.29 \mathrm{~nm}$ and $0.24 \mathrm{~nm}$ correspond to the (002) plane of graphitic carbon in the MWCNTs and the (103) plane of the hexagonal $\mathrm{MoSe}_{2}$ crystal, respectively (Fig. 5c and d). The selected area electron diffraction (SAED) pattern of the composite film showed concentric rings, indicating its polycrystalline nature (Fig. 5e). The elemental distribution of the MSNT composite sample was analyzed by obtaining its energy-filtered TEM (EFTEM) images (Fig. 5f-i), which confirmed the formation of the MSNT composite.

\subsection{Electrochemical analysis}

The performance of the MSNT electrode was analyzed using a conventional three-electrode system in a suitable electrolyte with an optimum concentration. Aqueous $\mathrm{LiCl}, \mathrm{Na}_{2} \mathrm{SO}_{4}, \mathrm{LiClO}_{4}$, $\mathrm{Na}_{2} \mathrm{SO}_{3}, \mathrm{H}_{2} \mathrm{SO}_{4}, \mathrm{KCl}$, and $\mathrm{NaOH}(1 \mathrm{M})$ were used as the electrolytes at a constant scan rate of $20 \mathrm{mV} \mathrm{s}^{-1}$ (Fig. 6a) under $\mathrm{Ag} /$ $\mathrm{AgCl}$ as reference electrode. The low thermodynamic stability of water is a major disadvantage for aqueous electrolytes. ${ }^{48}$ The thermodynamic stability of water under the potential limit varies as a function of the $\mathrm{pH}$ of the electrolyte solution. Therefore, the cyclic voltammetry (CV) curves of the MSNT electrode showed different potential windows for different electrolytes (Fig. 6a). Fig. 6b shows the specific capacitance values of the electrodes in the different electrolytes used. The aqueous $1 \mathrm{M} \mathrm{LiCl}$ electrolyte exhibited the highest specific capacity of $142 \mathrm{~mA} \mathrm{~h} \mathrm{~g}^{-1}$ at the scan rate of $20 \mathrm{mV} \mathrm{s}^{-1}$. It is wellknown that the specific capacity of an electrode is a chargedependent quantity, and the electrolyte concentration

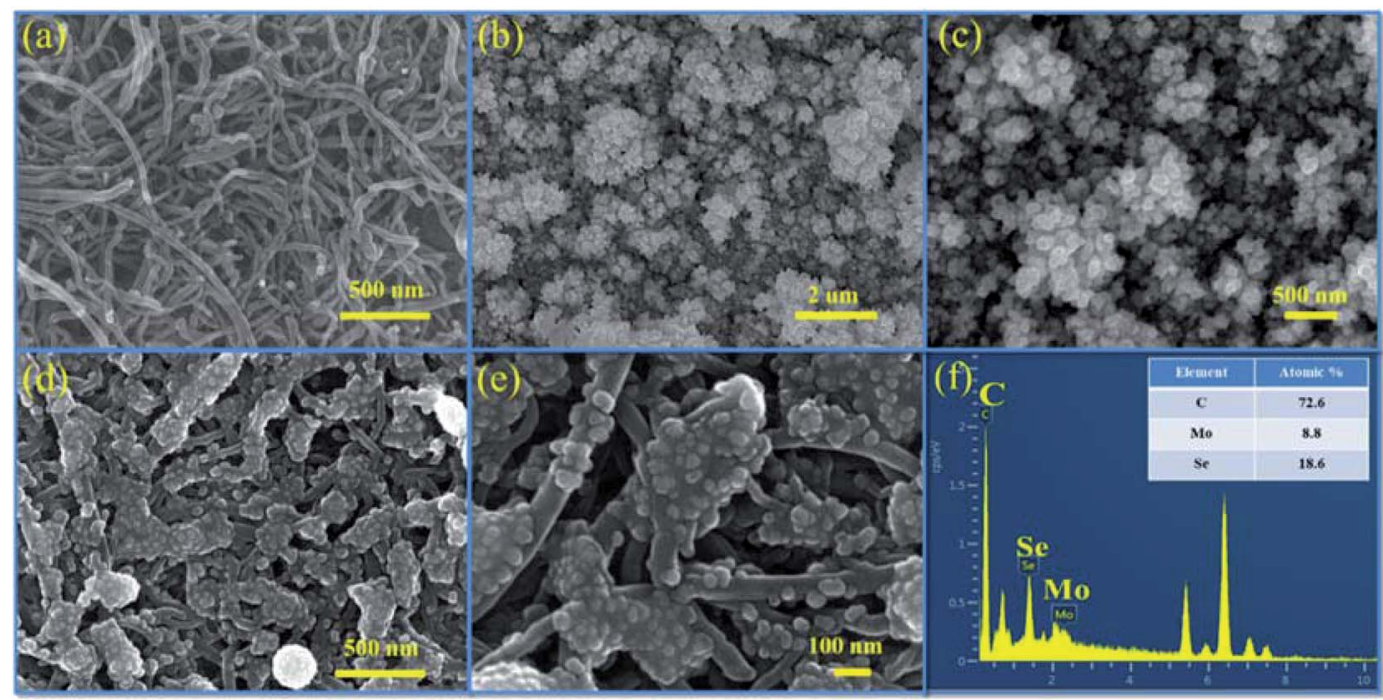

Fig. 4 FESEM images of (a) MWCNTs, ( $b$ and c) MoSe $e_{2}$ and ( $d$ and e) the MSNT composite thin film at different magnifications; and ( $f$ ) EDS mapping of the MSNT composite thin film. 


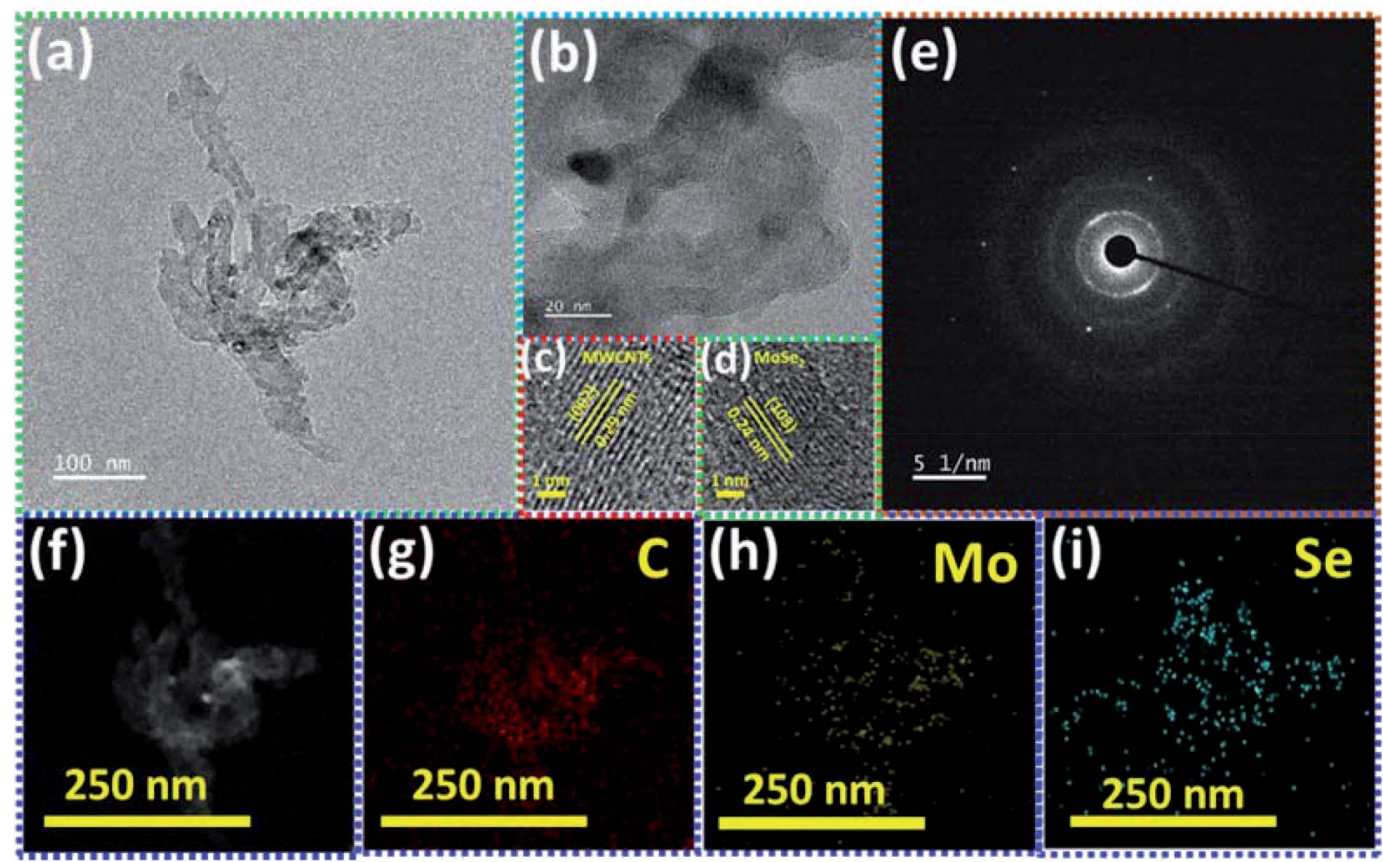

Fig. 5 (a) TEM and (b-d) high-resolution TEM images of the MSNT film with the corresponding enlarged view of the lattice fringes, (e) SAED pattern and $(f-i)$ EFTEM mapping of the MSNT film.

determines the quantity of charges. Hence, the effect of the LiCl concentration (0.5-2 M) on the CV performance of the MSNT composite electrode at a fixed scan rate of $20 \mathrm{mV} \mathrm{s}^{-1}$ was investigated (Fig. 6c). Fig. 6d shows the effect of the LiCl concentration on the specific capacity of the MSNT composite electrode. As can be observed from the figure, the specific capacity of the electrode increased with an increase in the LiCl concentration from 0.5 to $1 \mathrm{M}$. With a further increase in the LiCl concentration, the specific capacity of the electrode decreased. This is because at higher LiCl concentrations, the channels within the electrode layer were effectively consumed by the electrolyte ions. The ion activity decreased with an increase in the LiCl concentration because of the deceleration of the water hydration reaction, which reduced the mobility of
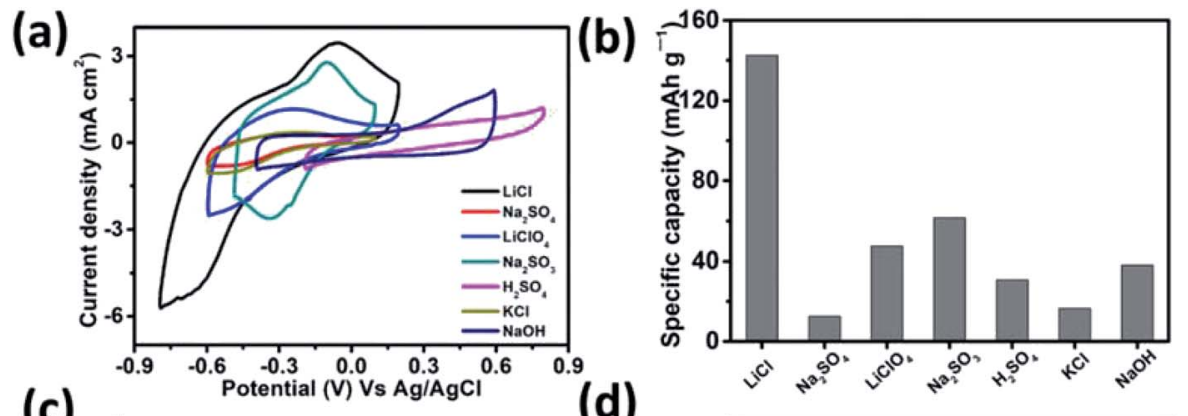

(c)
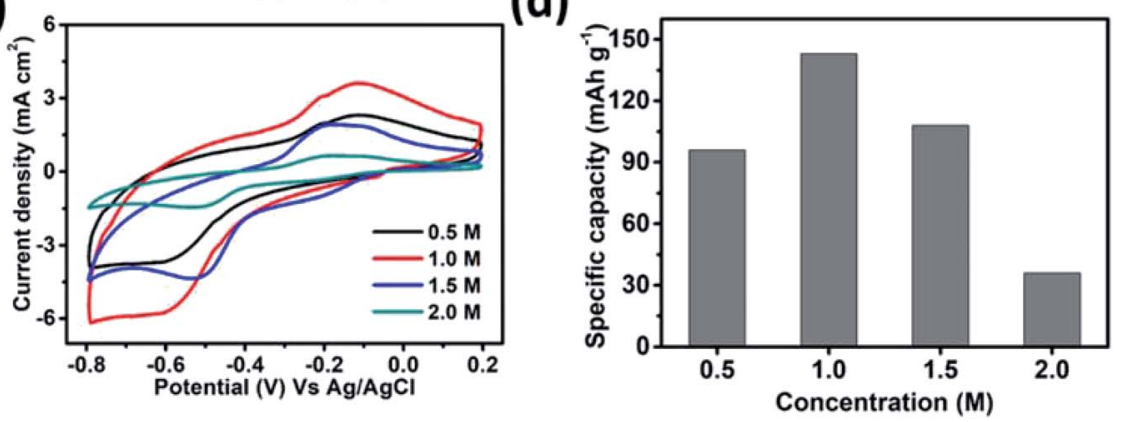

Fig. 6 (a) CV curves of the MSNT composite electrode in various electrolytes at a scan rate of $20 \mathrm{mV} \mathrm{s}^{-1}$, (b) specific capacity values for various electrolytes, (c) effect of the LiCl electrolyte concentration on the CV curves of the MSNT composite electrode at a scan rate of $20 \mathrm{mV} \mathrm{s}^{-1}$, and (d) the effect of the $\mathrm{LiCl}$ concentration on the specific capacity of the MSNT electrode. 
the electrolyte ions. ${ }^{6,46}$ The optimum $\mathrm{LiCl}$ concentration was found to be $1 \mathrm{M}$. This concentration was used for the electrochemical analyses of the $\mathrm{MoSe}_{2}$ and MSNT thin film electrodes.

The CV curves of the $\mathrm{MoSe}_{2}$ and MSNT electrodes at the fixed scan rate of $20 \mathrm{mV} \mathrm{s}^{-1}$ and over the potential range of -0.8 $0.2 \mathrm{~V}$ vs. $\mathrm{Ag} / \mathrm{AgCl}$ are shown in Fig. 7a. The MSNT electrode showed higher current distribution than the $\mathrm{MoSe}_{2}$ electrode because of the synergistic effect and good interfacial conjugation between $\mathrm{MoSe}_{2}$ and the MWCNTs. In the $1 \mathrm{M}$ aqueous $\mathrm{LiCl}$ electrolyte, the $\mathrm{MoSe}_{2}$ and MSNT electrodes showed a faradaic charge storage behavior characterized by two distinguishable oxidation and reduction peaks. Fig. 7b shows the CV curves of the MSNT composite electrode at different scan rates ranging from 5 to $100 \mathrm{mV} \mathrm{s}^{-1}$. The $\mathrm{CV}$ curves of the bare $\mathrm{MoSe}_{2}$ electrode is shown in the ESI S3 (Fig. S2 $\dagger$ ). The current distribution under the CV curves of both the electrodes increased with an increase in the scan rate, indicating the capacitive nature of the electrodes. In both the electrodes, two charge storage processes occurred during the $\mathrm{CV}$ cycling, as indicated by the shape of the $\mathrm{CV}$ curves of the electrodes. ${ }^{49}$ One of these processes could be attributed to the surface adsorption at the interface between the electrode and the electrolyte. A double layer was formed at the electrode/electrolyte interface.

$$
\left(\mathrm{MoSe}_{2}\right)_{\text {surface }}+x \mathrm{Li}^{+}+x \mathrm{e}^{-} \rightleftharpoons\left(\mathrm{Li}_{x}-\mathrm{MoSe}_{2}\right)_{\text {surface }}
$$

The second process corresponded to the reversible faradaic reaction based on the intercalation/deintercalation of Li-ion species.

$$
\mathrm{MoSe}_{2}+x \mathrm{Li}^{+}+x \mathrm{e}^{-} \rightleftharpoons \mathrm{Li}_{x} \mathrm{MoSe}_{2}
$$

Thus, the electrochemical properties of these electrodes were achieved by utilizing the overall mass of the electrode material through the surface adsorption and intercalation processes. Fig. 7c shows the correlation between the gravimetric capacity and scan rate for both the electrodes. The MSNT composite electrode showed the maximum capacitance, which was more than two times higher than that of the bare $\mathrm{MoSe}_{2}$ electrode. The capacitance decreased with an increase in the scan rate. At higher scan rates, the ion concentration on the surface of the electrode decreased with an increase in the current, and the ions diffused slowly during the charge-discharge process. In addition, a decrease in the capacitance was observed with an increase in the scan rate because the inner active sites of the electrode could not be sufficiently utilized and could not sustain the complete intercalation/deintercalation process at high scan rates because of time constraints. ${ }^{50}$ The unique nanostructure with lichen-like $\mathrm{MoSe}_{2}$ on the 1D porous MWCNT network facilitated rapid ion/electron transfer for the intercalation/ deintercalation of ions and induced a strong synergistic effect, thus improving the electrochemical properties of the MSNT composite electrode. ${ }^{51}$ Thus, a very high capacitance of $690 \mathrm{~F} \mathrm{~g}^{-1}$ was obtained at a low scan rate of $5 \mathrm{mV} \mathrm{s}^{-1}$ because of the effective utilization of all the active sites. The charge storage mechanisms of the electrodes were examined by obtaining their CV curves. The relationship between the current and scan rate can be expressed as follows. ${ }^{52}$

$$
I=a \nu^{b}
$$

where, ' $a$ ' and ' $b$ ' are the adjustable parameters calculated from the $\log (I)$ vs. $\log$ (scan rate) plot shown in Fig. $7 \mathrm{~d}$. The $b$-value is important to investigate the charge storage kinetics of an electrode. A $b$-value of 1 denotes a capacitive current, while $b=0.5$ implies that the current generated during charge storage is diffusion-controlled. As can be observed from Fig. 7d, the $b$ values for the anodic peak currents of the $\mathrm{MoSe}_{2}$ and MWCNTs
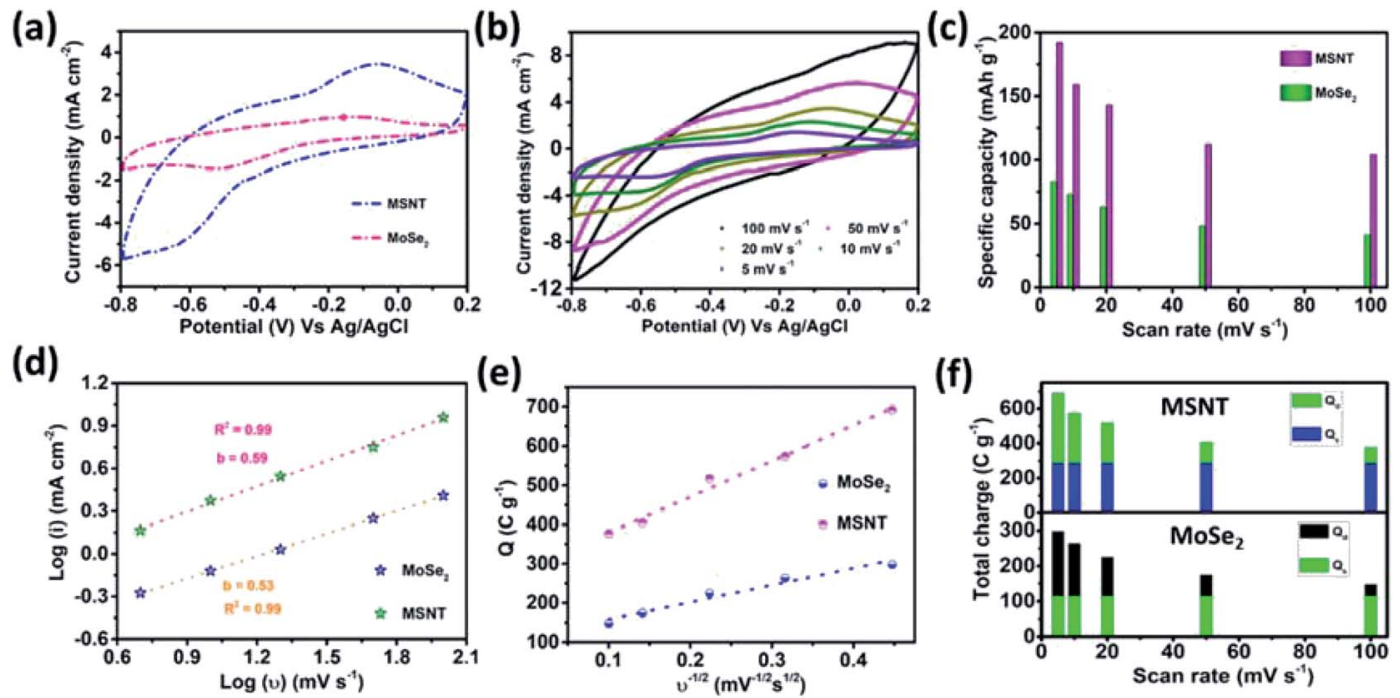

(f)

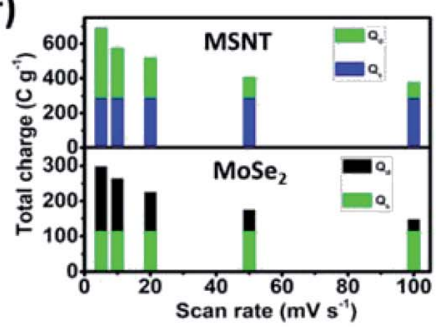

Fig. 7 (a) CV curves for the MoSe 2 and MSNT electrodes obtained at a constant scan rate of $20 \mathrm{mV} \mathrm{s}^{-1}$, (b) CV curves for the MSNT electrode at the scan rates ranging from 5 to $100 \mathrm{mV} \mathrm{s}^{-1}$, and (c) specific capacity values of the MoSe $\mathrm{C}_{2}$ and MSNT electrodes at different scan rates, (d) determination of the $b$-value from the $\log (i) v s$. $\log (\nu)$ plots of the electrodes, (e) total charge stored vs. reciprocal square root of scan rate $(Q$ vs. $\left.\nu^{-1 / 2}\right)$ plots of the electrodes, and (f) contribution of the surface capacitive $\left(Q_{s}\right)$ and diffusion-controlled $\left(Q_{d}\right)$ charges to the total charge $\left(Q_{t}\right)$. 
electrodes were 0.53 and 0.59 , respectively. This indicates that both the electrodes showed diffusion-controlled charge storage kinetics. The total charge $\left(Q_{\mathrm{t}}\right)$ of the electrodes was contributed by the surface capacitive $\left(Q_{\mathrm{s}}\right)$ and diffusion-controlled $\left(Q_{\mathrm{d}}\right)$ kinetics occurring at the electrode/electrolyte interface.

$$
Q_{\mathrm{t}}=Q_{\mathrm{s}}+Q_{\mathrm{d}}
$$

Considering the semi-infinite linear diffusion, the $Q_{\mathrm{s}}$ of the electrodes could be determined by plotting the graph of $Q_{\mathrm{t}}$ as a function of the reciprocal square root of the scan rate, as shown in Fig. 7e.

$$
Q_{\mathrm{t}}=Q_{\mathrm{s}}+c v^{-1 / 2}
$$

The surface capacitive and diffusion-controlled charges contributed to the total charge stored by the $\mathrm{MoSe}_{2}$ and MSNT electrodes (Fig. 7f), indicating that the charge storage mechanisms of the electrodes were mainly governed by their redox reactions.

The correlation between the potential of the electrodes and time at the constant current densities of $2-5 \mathrm{~mA} \mathrm{~cm}{ }^{-2}$ was investigated by obtaining their galvanostatic charge-discharge (GCD) curves. Fig. 8a shows the GCD curves of the MSNT composite electrode. The deviated triangular shape of the curves was due to the faradaic charge storage behavior of the MSNT electrode. In addition, the discharge curve of the electrode could be divided into three parts (Fig. 8a)-(I) an initial potential drop due to the internal resistance of the electrode, (II) a linear deviation because of the charge separation due to the non-faradaic reaction at the interface between the electrode and the electrolyte, and (III) an inclined aberration indicating the faradaic charge storage caused by the reversible intercalation/ deintercalation of $\mathrm{Li}^{+}$ions. ${ }^{53-55}$ Fig. 8b shows the specific capacities of the MSNT electrode at various current densities, as calculated from its GCD curves. The electrode showed a maximum specific capacity of $171 \mathrm{~mA} \mathrm{~h} \mathrm{~g}^{-1}$ at $5 \mathrm{~A} \mathrm{~g}^{-1}$ and could retain a specific capacity of $130 \mathrm{~mA} \mathrm{~h} \mathrm{~g}^{-1}$ at a high current density of $12.5 \mathrm{~mA} \mathrm{~h} \mathrm{~g}^{-1}$.

Long-term electrochemical stability is a prerequisite for realizing the practical applications of an electrode. The stability of the MSNT electrode was investigated over $2000 \mathrm{CV}$ cycles at a fixed scan rate of $100 \mathrm{mV} \mathrm{s}^{-1}$ in a $1 \mathrm{M}$ aqueous LiCl electrolyte. Fig. 8c shows the capacity retention of the electrodes over 2000 CV cycles. The MSNT composite electrode showed a capacity retention of $88 \%$, which was higher than that of the bare $\mathrm{MoSe}_{2}$ electrode (80\%). The improved stability of the MSNT electrode compared to that of the bare $\mathrm{MoSe}_{2}$ electrode can be attributed to the strong synergistic effect and interfacial conjugation between $\mathrm{MoSe}_{2}$ and the MWCNTs.

Electrochemical impedance spectroscopy (EIS) was used to analyze the capacitive and resistance parameters of the electrodes over the frequency range of $0.1 \mathrm{mHz}$ to $10 \mathrm{kHz}$ at the bias potentials of 0 and $10 \mathrm{mV}$. Fig. $8 \mathrm{~d}$ shows the imaginary $\left(Z^{\prime \prime}\right)$ and real $\left(Z^{\prime}\right)$ parts of the impedance of the $\mathrm{MoSe}_{2}$, and MSNT electrodes. The Nyquist plots of the electrodes showed an intercept with a semicircular arc in the high-frequency region and a straight line in the low-frequency region. The non-zero intercept on the real-axis indicates the equivalent series resistance $\left(R_{\mathrm{S}}\right)$, which is the combination of the solution resistance, internal resistance of the active electrode, and the resistance between the active electrode and the current collector. The semicircle corresponds to the faradaic reversible reaction that occurs during the charge storage and the diameter of the semicircle indicates the charge transfer resistance $\left(R_{\mathrm{ct}}\right)$ associated with the electrode parallel to the double-layer capacitor $\left(C_{\mathrm{dl}}\right)$. The $R_{\mathrm{s}}$ and $R_{\mathrm{ct}}$ values of the MoSe ${ }_{2}$, and MSNT electrodes were 0.95 and 0.41 ; and 2.71 and $2.01 \Omega$ respectively. These considerably small $R_{\mathrm{S}}$ and $R_{\mathrm{ct}}$ values indicate an intimate interfacial contact between the electrode and the $\mathrm{Li}^{+}$ions in the electrolyte..$^{5,56}$
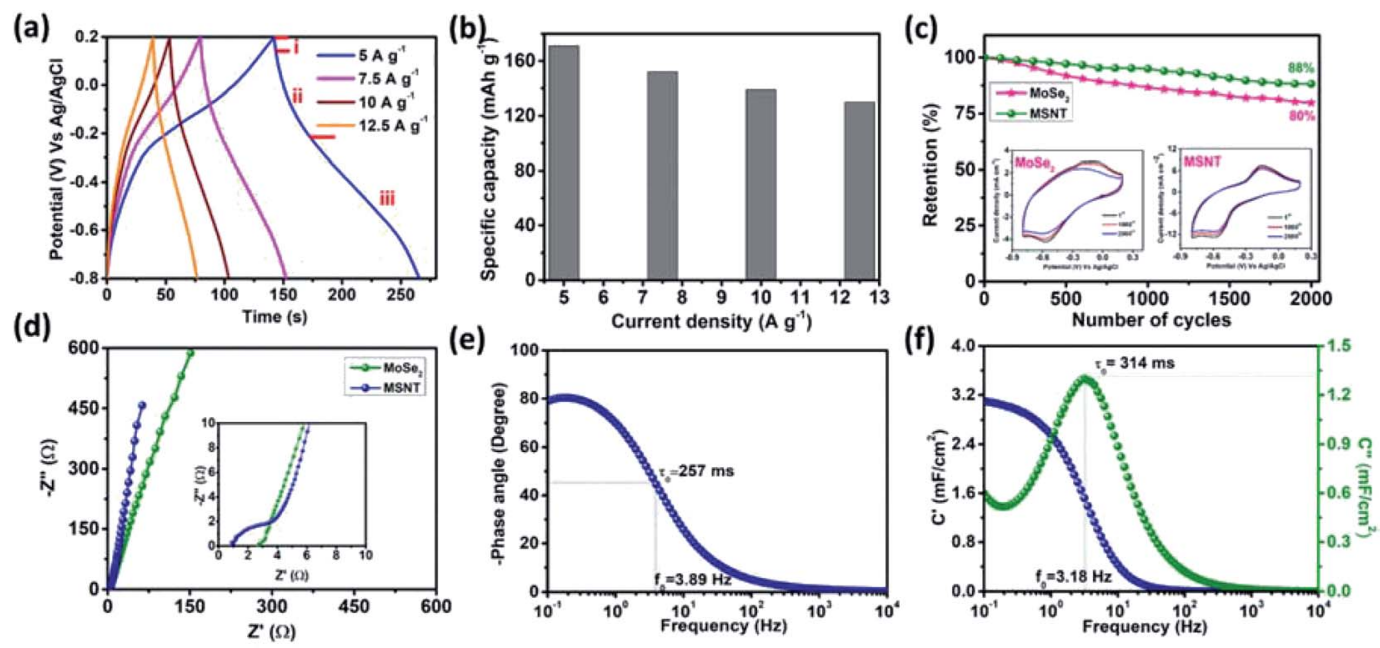

Fig. 8 (a) Charge-discharge profiles of the MSNT electrode at current densities ranging from 2 to $5 \mathrm{~mA} \mathrm{~cm}^{-2}$, (b) specific capacity of the MSNT electrode as a function of the current density (from 5-12.5 A g ${ }^{-1}$ ), (c) cyclic retention of the MoSe 2 and MSNT electrodes over 2000 cycles at a fixed scan rate of $100 \mathrm{mV} \mathrm{s}^{-1}$; the inset shows the change in the CV curves after cycling, (d) Nyquist plot for the MoSe 2 and MSNT electrodes, (e) Bode plot of the MSNT electrode, and (f) real and imaginary parts of the capacitances $\left(C^{\prime}\right.$ and $\left.C^{\prime \prime}\right)$ vs. frequency plot for the MSNT electrode. 
The frequency-dependent phase angles of the electrodes were determined by obtaining their Bode plots (Fig. 8e). The phase angle of the MSNT electrode increased with a decrease in the frequency and became approximately $-90^{\circ}$ as the frequency approached the minimum value. This indicates that the MSNT electrode showed a capacitive behavior of the MSNT electrode. ${ }^{57-59}$ Additionally, the steeply oblique line at low frequency region suggests the MSNT electrode reveals rapid response of electrolyte ion diffusion during charge-discharge. ${ }^{59}$ Furthermore, the ideal capacitive behavior of the electrode could be assessed by determining the frequency at which the phase angle crossed $45^{\circ} .^{58}$ The MSNT electrode exhibited a frequency of $3.89 \mathrm{~Hz}$ when the phase angle crossed $45^{\circ}$, indicating a capacitive behavior with rapid frequency response. Furthermore, the capacitive performance of the electrode could be evaluated by considering the real and imaginary parts of its capacitance with respect to the frequency:

$$
\begin{array}{r}
C(\omega)=C^{\prime}(\omega)-j C^{\prime \prime}(\omega) \\
C^{\prime}(\omega)=\frac{Z^{\prime \prime}(\omega)}{\omega|Z(\omega)|^{2}} \\
C^{\prime \prime}(\omega)=\frac{Z^{\prime}(\omega)}{\omega|Z(\omega)|^{2}}
\end{array}
$$

where $|Z(\omega)|=Z^{\prime}(\omega)+Z^{\prime \prime}(\omega)$ is the complex impedance; $\omega=2 \pi f$, where $f$ is the frequency; $Z^{\prime}$ and $Z^{\prime \prime}$ are the real and imaginary parts of the impedance in the Nyquist plot, respectively; $C^{\prime}(\omega)$ is the real accessible capacitance of the electrode; and $C^{\prime \prime}(\omega)$ is the imaginary part of the capacitance corresponding to the energy loss due to the irreversible process of the electrode. The frequency-dependence of the real and imaginary parts of the capacitance $\left(C^{\prime}\right.$ and $\left.C^{\prime \prime}\right)$ of the MSNT electrode is shown in Fig. 8f. The plot showed relaxation-type dispersions, where the real part of the capacitance reached a maximum value at lower frequencies and decreased with an increase in the frequency. This indicates that the electrode acted as an open circuit in the low-frequency region when the utilization of the electrode material was the maximum. When the utilization of the electrode material was the least, the electrode acted as a short circuit in the high-frequency region. ${ }^{\mathbf{6 0 , 6 1}}$ The imaginary part of the capacitance showed a maximum value at a frequency of $3.18 \mathrm{~Hz}$, which is comparable to that obtained in the Bode plot at the phase angle of $45^{\circ}$. The parameter $f_{0}$ is the characteristic frequency at which the time required to lose all the energy of the electrode is minimal. The term is known as the relaxation time constant and can be calculated using the following equation: $\tau_{0}$ $=1 / f_{0}$. The $\tau_{0}$ value of the hybrid MSNT electrode was $314 \mathrm{~ms}$, which was much lower than that of carbon electrodes such as rGO (430 ms) ${ }^{62}$ hybrid graphene $(392 \mathrm{~ms}),{ }^{63}$ and AC (700 ms). ${ }^{64}$ This indicates that the hybrid MSNT electrode showed excellent charge-discharge rate.

\subsection{Symmetric and asymmetric supercapacitor cell}

The potential of the MSNT composite electrode for supercapacitor applications was evaluated by fabricating a symmetric supercapacitor cell. The symmetric cell was fabricated using the MSNT composite as both the cathode and anode separated by a Whatman filter paper soaked with $1 \mathrm{M}$ aqueous $\mathrm{LiCl}$ as the electrolyte. Fig. 9a shows the CV curves of the cell at scan rates in the range of 5-100 $\mathrm{mV} \mathrm{s}^{-1}$ over the potential window of $0-1 \mathrm{~V}$.
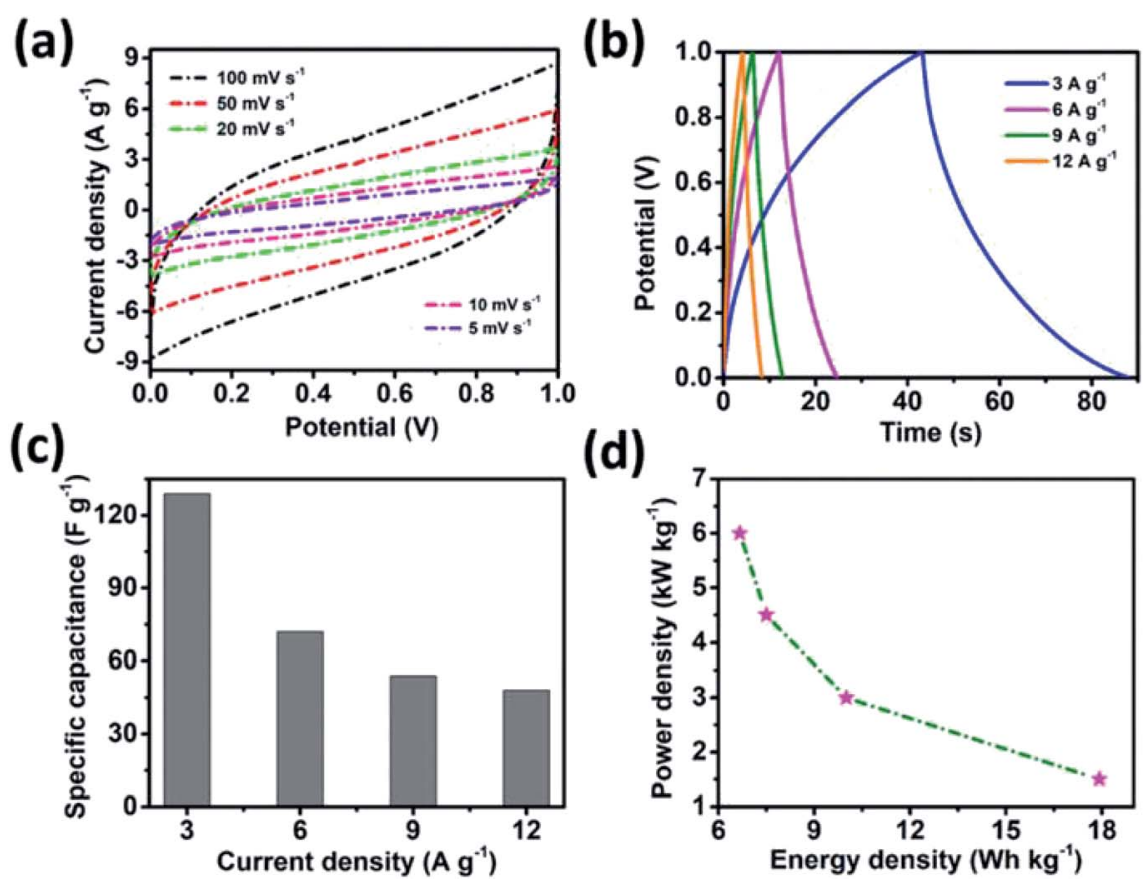

Fig. 9 Electrochemical characterizations of the MSNT//MSNT symmetric cell. (a) CV curves at different scan rates ranging from 5 to $100 \mathrm{mV} \mathrm{s}^{-1}$, (b) GCD curves at various current densities (3-12 $\mathrm{A} \mathrm{g}^{-1}$ ), (c) specific capacitance values from the GCD plot, and (d) Ragone plot of the MSNT// MSNT symmetric cell. 
These curves indicated that the cell showed a pure capacitive behavior. The shape of the CV curves remained almost constant at different scan rates, indicating that the cell showed significant reversibility. Furthermore, the GCD plots of the MSNT symmetric cell at different current densities $\left(3-12 \mathrm{~A} \mathrm{~g}^{-1}\right)$ are shown in Fig. 9b. The MSNT symmetric cell delivered a maximum specific capacitance of $129 \mathrm{~F} \mathrm{~g}^{-1}$ at $3 \mathrm{~A} \mathrm{~g}^{-1}$ (Fig. 9c). The Ragone plots of the cell showing the correlation between its specific energy and specific power are shown in Fig. 9d. The MSNT symmetric cell delivered a significant specific energy of $17.9 \mathrm{~W} \mathrm{~h} \mathrm{~kg}^{-1}$ at a specific power of $1.5 \mathrm{~kW} \mathrm{~kg}^{-1}$. Table 1 lists the specific capacitance, specific energy, and specific power of the MSNT symmetric cell.

An asymmetric supercapacitor cell was employed to achieve a high energy density over a wide working potential window. A $\mathrm{MnO}_{2}$ thin film was used as the positive electrode to fabricate the $\mathrm{MSNT} / / \mathrm{MnO}_{2}$ asymmetric supercapacitor. ${ }^{65}$ The charge contribution of the positive $\left(\mathrm{MnO}_{2}\right)$ and negative (MSNT) electrodes (CV curves) and the potential stability of the asymmetric cell (GCD plots) are shown in Fig. S3 (ESI S4 $\dagger$ ). The CV curves of the cell at different scan rates $\left(5-100 \mathrm{mV} \mathrm{s}^{-1}\right)$ are shown in Fig. 10a. The asymmetric cell showed a wide potential window of $1.6 \mathrm{~V}$ with no significant polarization. In addition, the shape of the $\mathrm{CV}$ curves remained unchanged at high scan rates,

Table 1 Electrochemical parameters of the MSNT//MSNT symmetric cell

\begin{tabular}{llll}
\hline $\begin{array}{l}\text { Current density } \\
\left(\mathrm{A} \mathrm{g}^{-1}\right)\end{array}$ & $\begin{array}{l}\text { Specific capacitance } \\
\left(\mathrm{F} \mathrm{g}^{-1}\right)\end{array}$ & $\begin{array}{l}\text { Energy density } \\
\left(\mathrm{W} \mathrm{h} \mathrm{kg}^{-1}\right)\end{array}$ & $\begin{array}{l}\text { Power density } \\
\left(\mathrm{W} \mathrm{kg}^{-1}\right)\end{array}$ \\
\hline 2 & 129 & 17.9 & 1500 \\
6 & 72 & 10 & 3000 \\
9 & 54 & 7.5 & 4500 \\
12 & 48 & 6.7 & 6000
\end{tabular}

indicating the excellent rate capability of the fabricated asymmetric cell. Fig. 10b shows the GCD plots of the MSNT//MnO asymmetric cell at different current densities ranging from 1.5 to $15.3 \mathrm{~A} \mathrm{~g} \mathrm{~g}^{-1}$. The specific capacitance of the cell is shown in Fig. 10c. The maximum specific capacitance of $112 \mathrm{~F} \mathrm{~g}^{-1}$ was achieved at the current density of $1.5 \mathrm{~A} \mathrm{~g}^{-1}$. The cell retained a specific capacitance of $19 \mathrm{~F} \mathrm{~g}^{-1}$ at $15.3 \mathrm{~A} \mathrm{~g}^{-1}$. The inset of Fig. 10d shows the Ragone plot (specific energy vs. specific power) of the cell. The MSNT//MnO 2 cell showed a maximum specific energy of $35.6 \mathrm{~W} \mathrm{~h} \mathrm{~kg}^{-1}$ at the power density of $964 \mathrm{~W}$ $\mathrm{kg}^{-1}$ and maintained a significant specific energy of $5.7 \mathrm{~W} \mathrm{~h} \mathrm{~kg}^{-1}$ even at the high power density of $9327 \mathrm{~W} \mathrm{~kg}^{-1}$. The asymmetric cell showed a significantly higher specific energy than the symmetric MSNT supercapacitor cell because of its wide working potential. The $\mathrm{MSNT} / / \mathrm{MnO}_{2}$ asymmetric cell could retain up to $90-96 \%$ of its energy efficiency (Fig. 10d). This indicated that the asymmetric cell showed minimum energy loss during the discharging process. Table 2 lists the specific capacitance, specific energy, and specific power of the MSNT/ $\mathrm{MnO}_{2}$ asymmetric cell. The long-term cycling stability of the cell was evaluated by obtaining its $\mathrm{CV}$ curves at a fixed scan rate of $100 \mathrm{mV} \mathrm{s}^{-1}$ for 2000 cycles (Fig. 10e). The MSNT//MnO asymmetric cell could retain $80 \%$ capacitance after 2000 cycles.

Table 2 Electrochemical parameters of the $\mathrm{MSNT} / / \mathrm{MnO}_{2}$ asymmetric cell

\begin{tabular}{llll}
$\begin{array}{l}\text { Current density } \\
\left(\mathrm{A} \mathrm{g}^{-1}\right)\end{array}$ & $\begin{array}{l}\text { Specific capacitance } \\
\left(\mathrm{F} \mathrm{g}^{-1}\right)\end{array}$ & $\begin{array}{l}\text { Energy density } \\
\left(\mathrm{W} \mathrm{h} \mathrm{kg}^{-1}\right)\end{array}$ & $\begin{array}{l}\text { Power density } \\
\left(\mathrm{W} \mathrm{kg}^{-1}\right)\end{array}$ \\
\hline & & & \\
1.5 & 112 & 35.6 & 964 \\
3.8 & 62 & 17.8 & 2347 \\
7.6 & 34 & 9.9 & 4752 \\
11.5 & 24 & 6.8 & 6994 \\
15.3 & 19 & 5.7 & 9327
\end{tabular}

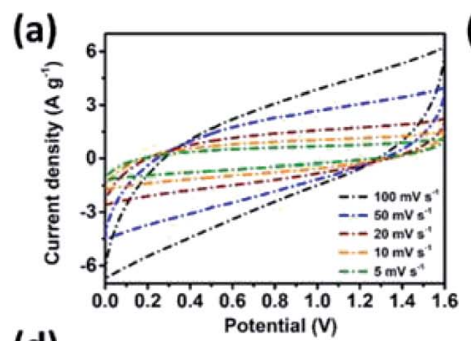

(d)

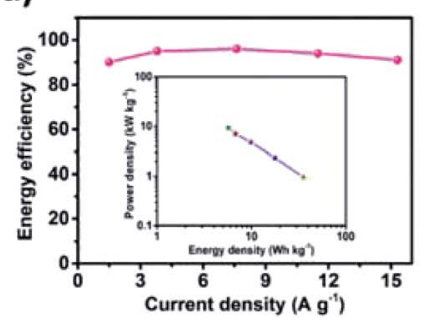

(b)

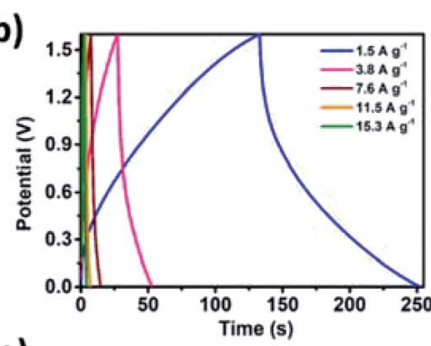

(e)

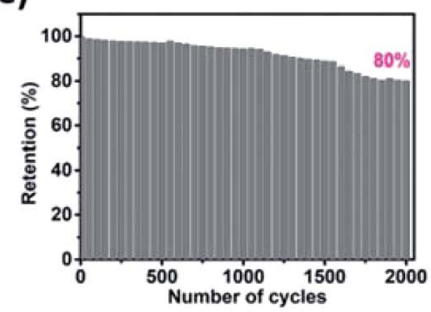

(c)

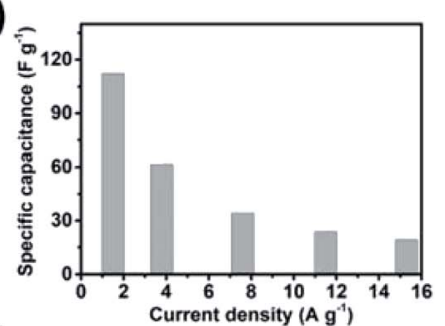

(f)

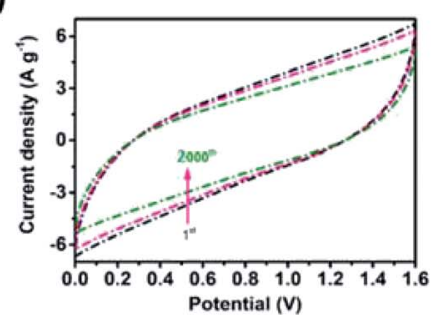

Fig. 10 Electrochemical characterizations of the $\mathrm{MSNT} / / \mathrm{MnO}_{2}$ asymmetric cell. (a) CV curves at different scan rates ranging from 5 to $100 \mathrm{mV}$ $\mathrm{s}^{-1}$, (b) GCD curves at various current densities (from 1.5 to $15.3 \mathrm{~A} \mathrm{~g}^{-1}$ ), (c) specific capacitance values from the GCD plot, and (d) energy efficiency vs. current density curves; the inset shows the Ragone plot of the cell, (e) capacitance retention performance of the cell over 2000 cycles, and (f) charge of the cell after 2000 cycles at a fixed scan rate of $100 \mathrm{mV} \mathrm{s}^{-1}$. 
Table 3 Electrochemical performance of the $\mathrm{MnO}_{2} / / \mathrm{MSNT}$ asymmetric supercapacitor cell and cells from literature

\begin{tabular}{|c|c|c|c|c|c|c|}
\hline Cell configuration & Electrolyte & $\begin{array}{l}\text { Cell potential } \\
\text { (V) }\end{array}$ & $\begin{array}{l}\text { Specific capacitance } \\
\left(\mathrm{F} \mathrm{g}^{-1}\right)\end{array}$ & $\begin{array}{l}\text { Energy density } \\
\left(\mathrm{W} \mathrm{h} \mathrm{kg}^{-1}\right)\end{array}$ & Stability retention@cycles & Ref. \\
\hline $\mathrm{MnO}_{2} / / \mathrm{MSNT}$ & $1 \mathrm{M} \mathrm{LiCl}$ & 1.6 & 112 & 35.6 & 80\%@2000 & This work \\
\hline $\mathrm{Ni}_{2} \mathrm{P} / / \mathrm{AC}$ & $6 \mathrm{M} \mathrm{KOH}$ & 1.4 & 96 & 26 & 91\%@5000 & 7 \\
\hline $\mathrm{NiCo}_{2} \mathrm{O}_{4}-\mathrm{rGO} / / \mathrm{AC}$ & $1 \mathrm{M} \mathrm{NaOH}$ & 1.7 & - & 12 & - & 66 \\
\hline $\mathrm{NiCO}_{2} \mathrm{O}_{4} / \mathrm{AC}$ & $1 \mathrm{M} \mathrm{NaOH}$ & 1.7 & - & 17.72 & 100\%@2000 & 67 \\
\hline $\mathrm{RuCo}_{2} \mathrm{O}_{4} / / \mathrm{AC}$ & $2 \mathrm{M} \mathrm{KOH}$ & 1.4 & 133 & 32.6 & 82\%@2500 & 68 \\
\hline PPy-NTs//N-CNT & $1 \mathrm{M} \mathrm{H}_{2} \mathrm{SO}_{4}$ & 1.4 & 109 & 28.95 & 90\%@2000 & 69 \\
\hline $\mathrm{Co}(\mathrm{OH})_{2} / / \mathrm{GO}$ & $1 \mathrm{M} \mathrm{KOH}$ & 1.2 & 59 & 11.9 & - & 70 \\
\hline $\mathrm{Ni}(\mathrm{OH})_{2}-\mathrm{CNT} / / \mathrm{rGO}$ & $1 \mathrm{M} \mathrm{KOH}$ & 1.8 & 78 & 35.24 & - & 71 \\
\hline $\mathrm{ZnCo}_{2} \mathrm{O}_{4} / / \mathrm{AC}$ & $3 \mathrm{M} \mathrm{KOH}$ & 1.6 & 82 & 27.78 & 178\%@2000 & 72 \\
\hline $\mathrm{NoCo}_{2} \mathrm{~S}_{4} / / \mathrm{AC}$ & $3 \mathrm{M} \mathrm{KOH}$ & 1.6 & 72 & 25.5 & 86\%@4000 & 73 \\
\hline$\alpha-\mathrm{NiMoO}_{4} / / \mathrm{rGO}$ & $3 \mathrm{M} \mathrm{KOH}$ & 1.1 & 73 & 12.31 & 85\%@2000 & 74 \\
\hline $\mathrm{NaMnO}_{2} / / \mathrm{AC}$ & $0.5 \mathrm{M} \mathrm{Na}_{2} \mathrm{SO}_{4}$ & 1.9 & 39 & 19.5 & 97\%@10 000 & 75 \\
\hline $\mathrm{Co}_{0.1} \mathrm{Ni}_{0.9} \mathrm{P} / / \mathrm{AC}$ & $2 \mathrm{M} \mathrm{KOH}$ & 1.4 & 119 & 32.2 & 72\%@10 000 & 8 \\
\hline $\mathrm{FeCo}_{2} \mathrm{O}_{4} / / \mathrm{AC}$ & $6 \mathrm{M} \mathrm{KOH}$ & 1.4 & 88 & 24 & 94\%@5000 & 76 \\
\hline NiP-CNT//CoP-CNT & $2 \mathrm{M} \mathrm{KOH}$ & 1.4 & 151 & 41.1 & 70\%@10 000 & 9 \\
\hline
\end{tabular}

The effect of cycling on the CV curves of the cell is shown in Fig. 10f. The area of the CV curve decreased with an increase in the number of cycles because of the degradation of the electrode material during cycling. Table 3 summarize the electrochemical performance of the $\mathrm{MnO}_{2} / / \mathrm{MSNT}$ asymmetric supercapacitor cell and cells from literature. ${ }^{7-9,66-76}$

\section{Conclusion}

In this study, we developed a novel simple, scalable, and efficient approach to prepare composite electrodes with excellent charge storage performance. We synthesized MSNT composite thin films using the SILAR method for supercapacitor applications. $\mathrm{MoSe}_{2}$ (lichen-like growth) was deposited on a MWCNT nanonetwork, and the resulting MSNT film showed excellent electrochemical properties such as a specific capacity of $192 \mathrm{~mA} \mathrm{~h}^{-1}$ and a cyclic stability of $88 \%$. This excellent electrochemical performance of the composite film can be attributed to the large surface area of the MWCNT nanonetwork with a good conductive path and the effective synergistic effect and interfacial conjugation between $\mathrm{MoSe}_{2}$ and the MWCNTs. This study provides a new pathway for the synthesis of hybrid carbon- and metal selenide-based thin films for energy storage applications. Inspired by the enhanced electrochemical performance of the MSNT composite electrode, an aqueous asymmetric cell was fabricated using $\mathrm{MnO}_{2}$ as the pseudocapacitive positive electrode. The $\mathrm{MSNT} / / \mathrm{MnO}_{2}$ asymmetric cell delivered a high specific capacitance of $112 \mathrm{~F} \mathrm{~g}^{-1}$ with an energy density of $35.6 \mathrm{~W} \mathrm{~h} \mathrm{~kg}^{-1}$ and a capacitance retention of $80 \%$ after 2000 cycles.

\section{Conflicts of interest}

There are no conflicts of interest to declare.

\section{Acknowledgements}

This work was supported by a National Research Foundation (NRF) grant funded by the Ministry of Science, ICT, and Future Planning [grant number NRF-2018M3A7B4071535] and Priority Research Centers Program through the National Research Foundation of Korea [grant number NRF2019R1A6A1A11055660].

\section{References}

1 D. P. Dubal, O. Ayyad, V. Ruiz and P. Gomez-Romero, Hybrid energy storage: the merging of battery and supercapacitor chemistries, Chem. Soc. Rev., 2015, 44, 1777.

2 G. Derrien, J. Hassoun, S. Panero and B. Scrosati, "Nanostructured Sn-C Composite as an Advanced Anode Material in High-Performance Lithium-Ion Batteries, Adv. Mater., 2007, 19, 2336.

3 C. D. Lokhande, D. P. Dubal and O. S. Joo, Metal oxide thin film based supercapacitors, Curr. Appl. Phys., 2011, 11, 255.

4 J. Chang, M. Park, D. Ham, S. B. Ogale, R. S. Mane and S. M. Han, Liquid-phase synthesized mesoporous electrochemical supercapacitors of nickel hydroxide, Electrochim. Acta, 2008, 53, 5016.

5 M. Xu, T. Ling, M. Shi and H. Chen, Graphene-Like TwoDimensional Materials, Chem. Rev., 2013, 113, 3766.

6 S. S. Karade and B. R. Sankapal, Room temperature PEDOT: PSS encapsulated MWCNTs thin film for electrochemical supercapacitor, J. Electroanal. Chem., 2016, 771, 80.

7 K. Zhou, W. Zhou, L. Yang, J. Lu, S. Cheng, W. Mai, Z. Tang, L. Li and S. Chen, Ultrahigh-Performance Pseudocapacitor Electrodes Based on Transition Metal Phosphide Nanosheets Array via Phosphorization: A General and Effective Approach, Adv. Funct. Mater., 2015, 25, 7530.

8 N. Zhang, Y. Li, J. Xu, J. Li, B. Wei, Y. Ding, I. Amorim, R. Thomas, S. M. Thalluri, Y. Liu, G. Yu and L. Liu, High Performance Flexible Solid-State Asymmetric 
Supercapacitors Based on Bi-Metallic Transition Metal Phosphide Nanocrystals, ACS Nano, 2019, 13, 10612.

9 N. Zhang, J. Xu, B. Wei, J. Li, I. Amorim, R. Thomas, S. M. Thalluri, Z. Wang, W. Zhou, S. Xie and L. Liu, MilleCrêpe-like Metal Phosphide Nanocrystals/Carbon Nanotube Film Composites as High-Capacitance Negative Electrodes in Asymmetric Supercapacitors, ACS Appl. Energy Mater., 2020, 3, 4580.

10 D. P. Dubal, N. R. Chodankar, D. H. Kim and P. GomezRomero, Towards flexible solid-state supercapacitors for smart and wearable electronics, Chem. Soc. Rev., 2018, 47, 2065.

11 S. H. Ng, J. Wang, D. Wexler, K. Konstantinov, Z. P. Guo and H. K. Liu, "Highly reversible lithium storage in spheroidal carbon-coated silicon nanocomposites as anodes for lithium-ion batteries", Angew. Chem., Int. Ed., 2006, 45, 6896.

12 K. F. Mak, K. L. He, J. Shan and T. F. Heinz, Control of valley polarization in monolayer $\mathrm{MoS}_{2}$ by optical helicity, Nat. Nanotechnol., 2012, 7, 494.

13 H. L. Zeng, J. F. Dai, W. Yao, D. Xiao and X. D. Cui, Valley polarization in $\mathrm{MoS}_{2}$ monolayers by optical pumping, Nat. Nanotechnol., 2012, 7, 490.

14 S. Ithurria, M. D. Tessier, B. Mahler, R. Lobo, B. Dubertret and A. Efros, Colloidal nanoplatelets with two-dimensional electronic structure, Nat. Mater., 2011, 10, 936.

15 B. Radisavljevic, S. Radenovic, J. Brivio, V. Giacometti and A. Kis, Single-layer $\mathrm{MoS}_{2}$ transistors, Nat. Nanotechnol., 2011, 6, 147.

16 Y. Ding, Y. L. Wang, J. Ni, L. Shi, S. Q. Shi and W. H. Tang, First principles study of structural, vibrational and electronic properties of graphene-like $\mathrm{MX}_{2} \quad(\mathrm{M}=\mathrm{Mo}$, $\mathrm{Nb}, \mathrm{W}, \mathrm{Ta} ; \mathrm{X}=\mathrm{S}, \mathrm{Se}, \mathrm{Te})$ monolayers, Physica B, 2011, 403, 2254.

17 S. Z. Butler, S. M. Hollen, L. Cao, Y. Cui, J. A. Gupta, H. R. Gutiérrez, T. F. Heinz, S. S. Hong, J. Huang, A. F. Ismach, E. Johnston-Halperin, M. Kuno, V. V. Plashnitsa, R. D. Robinson, R. S. Ruoff, S. Salahuddin, J. Shan, L. Shi, M. G. Spencer, M. Terrones, W. Windl and J. E. Goldberger, Progress, challenges, and opportunities in two-dimensional materials beyond graphene, ACS Nano, 2013, 7, 2898.

18 M. Chhowalla, H. S. Shin, G. Eda, L. J. Li, K. P. Loh and H. Zhang, The chemistry of two-dimensional layered transition metal dichalcogenide nanosheets, Nat. Chem., 2013, 5, 263.

19 X. Huang, Z. Zeng and H. Zhang, Metal dichalcogenide nanosheets: preparation, properties and applications, Chem. Soc. Rev., 2013, 42, 1934.

20 C. Tan and H. Zhang, Two-dimensional transition metal dichalcogenide nanosheet-based composites, Chem. Soc. Rev., 2015, 44, 2713.

21 J. M. Soon and K. P. Loh, Electrochemical double-layer capacitance of $\mathrm{MoS}_{2}$ nanowall films, Electrochem. SolidState Lett., 2007, 10, 250.

22 M. Liu, G. Li and X. Chen, One-Pot Controlled Synthesis of Spongelike $\mathrm{CuInS}_{2}$ Microspheres for Efficient Counter
Electrode with Graphene Assistance in Dye-Sensitized Solar Cells, ACS Appl. Mater. Interfaces, 2014, 6, 2604.

23 B. Hu, X. Qin, A. M. Asiri, K. A. Alamry, A. O. Al-Youbi and X. Sun, " $\mathrm{WS}_{2}$ nanoparticles-encapsulated amorphous carbon tubes: A novel electrode material for supercapacitors with a high rate capability", Electrochem. Commun., 2013, 28, 75.

24 B. Hu, X. Qin, A. M. Asiri, K. A. Alamry, A. O. Al-Youbi and $\mathrm{X}$. Sun, Synthesis of porous tubular $\mathrm{C} / \mathrm{MoS}_{2}$ nanocomposites and their application as a novel electrode material for supercapacitors with excellent cycling stability, Electrochim. Acta, 2013, 100, 24.

25 K. J. Huang, J. Z. Zhang, G. W. Shi and Y. M. Liu, Hydrothermal synthesis of molybdenum disulfide nanosheets as supercapacitors electrode material, Electrochim. Acta, 2014, 132, 397.

26 K. J. Huang, L. Wang, Y. J. Liu, Y. M. Liu, H. B. Wang, T. Gan and L. L. Wang, Layered $\mathrm{MoS}_{2}$-graphene composites for supercapacitor applications with enhanced capacitive performance, Int. J. Hydrogen Energy, 2013, 38, 14027.

27 X. Zhou, B. Xu, Z. Lin, D. Shu and L. Ma, Hydrothermal synthesis of flower-like $\mathrm{MoS}_{2}$ nanospheres for electrochemical supercapacitors, J. Nanosci. Nanotechnol., 2014, 14, 250.

28 K. Gopalakrishnan, S. Sultan, A. Govindaraj and C. N. R. Rao, Supercapacitors based on composites of PANI with nanosheets of nitrogen-doped RGO, BC1. 5N, $\mathrm{MoS}_{2}$ and $\mathrm{WS}_{2}$, Nano Energy, 2015, 12, 52.

29 A. Ramadoss, T. Kim, G.-S. Kim and S. J. Kim, Enhanced activity of a hydrothermally synthesized mesoporous $\mathrm{MoS}_{2}$ nanostructure for high performance supercapacitor applications, New J. Chem., 2014, 38, 2379.

30 L. Cao, S. Yang, W. Gao, Z. Liu, Y. Gong, L. Ma, G. Shi, S. Lei, Y. Zhang, S. Zhang, R. Vajtai and P. M. Ajayan, "Direct Laser-Patterned Micro-Supercapacitors from Paintable $\mathrm{MoS}_{2}$ Films”, Small, 2013, 9, 2905.

31 S. K. Balasingam, J. S. Lee and Y. Jun, Few-layered $\mathrm{MoSe}_{2}$ nanosheets as an advanced electrode material for supercapacitors, Dalton Trans., 2015, 44, 15491.

32 S. K. Balasingam, J. S. Lee and Y. Jun, Molybdenum diselenide/reduced graphene oxide based hybrid nanosheets for supercapacitor applications, Dalton Trans., 2016, 45, 9646.

33 K. J. Huang, J. Z. Zhang and Y. Fan, Preparation of layered $\mathrm{MoSe}_{2}$ nanosheets on Ni-foam substrate with enhanced supercapacitor performance, Mater. Lett., 2015, 152, 244.

34 V. K. Mariappan, K. Krishnamoorthy, P. Pazhamalai, S. Sahoo and S. J. Kim, Electrodeposited molybdenum selenide sheets on nickel foam as a binder-free electrode for supercapacitor application, Electrochim. Acta, 2018, 265, 514.

35 X. Liu, J. Z. Zhang, K. J. Huang and P. Hao, "Net-like molybdenum selenide-acetylene black supported on $\mathrm{Ni}$ foam for high-performance supercapacitor electrodes and hydrogen evolution reaction", Chem. Eng. J., 2016, 302, 437.

36 H. Peng, J. Zhou, K. Sun, G. Ma, Z. Zhang, E. Feng and Z. Lei, High-Performance Asymmetric Supercapacitor Designed 
with a Novel NiSe@MoSe ${ }_{2}$ Nanosheet Array and NitrogenDoped Carbon Nanosheet, ACS Sustainable Chem. Eng., 2017, 5, 5951.

37 J. Shen, J. Wu, L. Pei, M. T. F. Rodrigues, Z. Q. Zhang, F. Zhang, X. Zhang, P. M. Ajayan and M. Ye, "CoNi ${ }_{2} \mathrm{~S}_{4}$-Graphene-2D-MoSe 2 as an Advanced Electrode Material for Supercapacitors", Adv. Energy Mater., 2016, 6, 1600341.

38 R. R. Salunkhe, J. Lin, V. Malgras, S. X. Dou, J. H. Kim and Y. Yamauchi, Large-scale synthesis of coaxial carbon nanotube $/ \mathrm{Ni}(\mathrm{OH})_{2}$ composites for asymmetric supercapacitor application, Nano Energy, 2015, 11, 211.

39 S. S. Karade and B. R. Sankapal, Materials Mutualism through EDLC-Behaved MWCNTs with Pseudocapacitive $\mathrm{MoTe}_{2}$ Nanopebbles: Enhanced Supercapacitive Performance, ACS Sustainable Chem. Eng., 2018, 6, 15072.

40 C. D. Jadhav, S. S. Karade, B. R. Sankapal, G. P. Patil and P. G. Chavan, Reduced turn-on field through solution processed $\mathrm{MoS}_{2}$ nanoflakes anchored MWCNTs, Chem. Phys. Lett., 2019, 723, 146.

41 P. P. Hankare, A. A. Patil, P. A. Chate, K. M. Garadkar, D. J. Sathe, A. H. Manikshete and I. S. Mulla, Characterization of $\mathrm{MoSe}_{2}$ thin film deposited at room temperature from solution phase, J. Cryst. Growth, 2008, 311, 15.

42 R. N. Bulakhe, V. H. Nguyen and J. J. Shim, Layer-structured nanohybrid $\mathrm{MoS}_{2} @$ rGO on 3D nickel foam for high performance energy storage applications, New J. Chem., 2017, 41, 1473.

43 S. V. Kite, P. A. Chate, K. M. Garadkar and D. J. Sathe, Effect of annealing temperature on properties of molybdenum disulfide thin films, J. Mater. Sci. Mater. Electron., 2017, 28, 16148.

44 K. Wang, J. Yang, J. Zhu, L. Li, Y. Liu, C. Zhang and T. Liu, General solution-processed formation of porous transitionmetal oxides on exfoliated molybdenum disulfides for high-performance asymmetric supercapacitors, J. Mater. Chem. A, 2017, 5, 11236.

45 A. Ouadah, J. C. Bernede, J. Pouzet and M. Morsli, MoTe 2 Thin Films Synthesized by Solid State Reactions between Mo and Te Thin Films, Phys. Status Solidi, 1992, 134, 455.

46 S. S. Karade, D. P. Dubal and B. R. Sankapal, "Decoration of Ultrathin $\mathrm{MoS}_{2}$ Nanoflakes over MWCNTs: Enhanced Supercapacitive Performance through Electrode to Symmetric All-Solid-State Device”, ChemistrySelect, 2017, 2, 10405.

47 S. S. Karade and B. R. Sankapal, Two dimensional cryptomelane like growth of $\mathrm{MoSe}_{2}$ over MWCNTs: Symmetric all-solid-state supercapacitor, J. Electroanal. Chem., 2017, 802, 131.

48 P. Ratajczak, M. E. Suss, F. kaasik and F. Beguin, Carbon electrodes for capacitive technologies, Energy Storage Mater., 2019, 16, 126.

49 W. Wei, X. Cui, W. Chen and D. G. Ivey, Manganese oxidebased materials as electrochemical supercapacitor electrodes, Chem. Soc. Rev., 2011, 40, 1697.
50 G. S. Gund, D. P. Dubal, S. S. Shinde and C. D. Lokhande, Architectured morphologies of chemically prepared $\mathrm{NiO} /$ MWCNTs nanohybrid thin films for high performance supercapacitors, ACS Appl. Mater. Interfaces, 2014, 6, 3176.

51 G. Z. Chen, Understanding supercapacitors based on nanohybrid materials with interfacial conjugation, Prog. Nat. Sci.: Mater. Int., 2013, 23, 245.

52 S. S. Karade, S. Lalwani, J. H. Eum and H. Kim, Deep eutectic solvent-assisted synthesis of $\mathrm{RuCo}_{2} \mathrm{O}_{4}$ : an efficient positive electrode for hybrid supercapacitors, Sustainable Energy Fuels, 2020, 4, 3066.

53 D. P. Dubal, V. J. Fulari and C. D. Lokhande, Effect of morphology on supercapacitive properties of chemically grown $\beta-\mathrm{Ni}(\mathrm{OH})_{2}$ thin films, Microporous Mesoporous Mater., 2012, 151, 511.

54 W. Sugimoto, H. Iwata, Y. Yasunaga, Y. Murakami and Y. Takasu, Preparation of ruthenic acid nanosheets and utilization of its interlayer surface for electrochemical energy storage, Angew. Chem., Int. Ed., 2003, 42, 4092.

55 S. S. Karade, A. Agarwal, B. Pandit, R. V. Motghare, S. A. Pande and B. R. Sankapal, First report on solution processed $\alpha-\mathrm{Ce}_{2} \mathrm{~S}_{3}$ rectangular microrods: An efficient energy storage supercapacitive electrode, J. Colloid Interface Sci., 2019, 535, 169.

56 S. J. Patil, V. C. Lokhande, N. R. Chodankar and C. D. Lokhande, Chemically prepared $\mathrm{La}_{2} \mathrm{Se}_{3}$ nanocubes thin film for supercapacitor application, J. Colloid Interface Sci., 2016, 469, 318.

57 S. J. Patil, A. C. Lokhande, D. W. Lee, J. H. Kim and C. D. Lokhande, Chemical synthesis and supercapacitive properties of lanthanum telluride thin film, J. Colloid Interface Sci., 2017, 490, 147.

58 M. Biswal, A. Banerjee, M. Deo and S. Ogale, From dead leaves to high energy density supercapacitors, Energy Environ. Sci., 2013, 6, 1249.

59 S. J. Patil, N. R. Chodankar, R. B. Pujari, Y.-K. Han and D. W. Lee, Core-shell hetero-nanostructured 1D transition metal polyphosphates decorated 2D bimetallic layered double hydroxide for sustainable hybrid supercapacitor, $J$. Power Sources, 2020, 466, 228286.

60 D. P. Dubal, N. R. Chodankar, A. Vinu, D. H. Kim and P. Gomez-Romero, Asymmetric supercapacitors based on reduced graphene oxide with different polyoxometalates as positive and negative electrodes, ChemSusChem, 2017, 10, 2742 .

61 D. P. Dubal, N. R. Chodankar and S. Qiao, Tungsten nitride nanodots embedded phosphorous modified carbon fabric as flexible and robust electrode for asymmetric pseudocapacitor, Small, 2019, 15, 1804104.

62 A. Muthurasu, P. Dhandapani and V. Ganesh, Facile and simultaneous synthesis of graphene quantum dots and reduced graphene oxide for bio-imaging and supercapacitor applications, New J. Chem., 2016, 40, 9111.

63 J. Yan, W. Sun, T. Wei, Q. Zhang, Z. Fan and F. Wei, Fabrication and electrochemical performances of hierarchical porous $\mathrm{Ni}(\mathrm{OH})_{2}$ nanoflakes anchored on graphene sheets, J. Mater. Chem., 2012, 22, 11494. 
64 T. M. Masikhwa, M. J. Madito, D. Y. Momodu, J. K. Dangbegnon, O. Guellati, A. Harat, M. Guerioune, F. Barzegar and N. Manyala, High performance asymmetric supercapacitor based on CoAl-LDH/GF and activated carbon from expanded graphite, RSC Adv., 2016, 6, 46723.

65 A. M. Patil, A. C. Lokhande, P. A. Shinde and C. D. Lokhande, Flexible Asymmetric Solid-State Supercapacitors by Highly Efficient 3D Nanostructured $\alpha-\mathrm{MnO}_{2}$ and h-CuS Electrodes, ACS Appl. Mater. Interfaces, 2018, 10, 16636.

66 C. C. Hu, C. T. Hsu, K. H. Chang and H. Y. Hsu, Microwaveassisted hydrothermal annealing of binary Ni-Co oxyhydroxides for asymmetric supercapacitors, $J$. Power Sources, 2013, 238, 180.

67 C. T. Hsu and C. C. Hu, Synthesis and characterization of mesoporous spinel $\mathrm{NiCo}_{2} \mathrm{O}_{4}$ using surfactant-assembled dispersion for asymmetric supercapacitors, $J$. Power Sources, 2013, 242, 662.

68 D. P. Dubal, N. R. Chodankar, R. Holze, D. H. Kim and P. Gomez-Romero, Ultrathin Mesoporous $\mathrm{RuCo}_{2} \mathrm{O}_{4}$ Nanoflakes: An Advanced Electrode for High-Performance Asymmetric Supercapacitors, ChemSusChem, 2017, 10, 1771.

69 D. P. Dubal, N. R. Chodankar, Z. Caban-Huertas, F. Wolfart, M. Vidotti, R. Holze, C. D. Lokhande and P. Gomez-Romero, Synthetic approach from polypyrrole nanotubes to nitrogen doped pyrolyzed carbon nanotubes for asymmetric supercapacitors, J. Power Sources, 2016, 308, 158.

70 R. R. Salunkhe, B. P. Bastakoti, C. T. Hsu, N. Suzuki, J. H. Kim, S. X. Dou, C. C. Hu and Y. Yamauchi, Direct Growth of Cobalt Hydroxide Rods on Nickel Foam and Its
Application for Energy Storage, Chem. - Eur. J., 2014, 20, 3084 .

71 R. R. Salunkhe, J. Lin, V. Malgras, S. X. Dou, J. H. Kim and Y. Yamauchi, Large-scale synthesis of coaxial carbon nanotube $/ \mathrm{Ni}(\mathrm{OH})_{2}$ composites for asymmetric supercapacitor application, Nano Energy, 2015, 11, 211.

72 Y. Shang, T. Xie, C. Ma, L. Su, Y. Gai, J. Liu and L. Gong, Synthesis of hollow $\mathrm{ZnCo}_{2} \mathrm{O}_{4}$ microspheres with enhanced electrochemical performance for asymmetric supercapacitor, Electrochim. Acta, 2018, 286, 103.

73 Z. Wu, X. Pu, X. Ji, Y. Zhu, M. Jing, Q. Chen and F. Jiao, High Energy Density Asymmetric Supercapacitors from Mesoporous $\mathrm{NiCo}_{2} \mathrm{~S}_{4}$ Nanosheets, Electrochim. Acta, 2015, 174, 238.

74 P. R. Jothi, K. Shanthi, R. R. Salunkhe, M. Pramanik, V. R. Malgras, S. M. Alshehri and Y. Yamauchi, Synthesis and Characterization of $\alpha-\mathrm{NiMoO}_{4}$ Nanorods for Supercapacitor Application, Eur. J. Inorg. Chem., 2015, 2015, 3694.

75 Q. T. Qua, Y. Shia, S. Tiana, Y. H. Chena, Y. P. Wua and R. Holze, A new cheap asymmetric aqueous supercapacitor: Activated carbon $/ / \mathrm{NaMnO}_{2}$, J. Power Sources, 2009, 194, 1222.

76 S. Tajik, D. P. Dubal, P. Gomez-Romero, A. Yadegari, A. Rashidi, B. Nasernejad, Inamuddin and A. M. Asiri, Nanostructured mixed transition metal oxides for high performance asymmetric supercapacitors: Facile synthetic strategy, Int. J. Hydrogen Energy, 2017, 42, 12384. 